\title{
Influence of the extracellular matrix on endogenous and transplanted stem cells after brain damage
}

\author{
Lars Roll ${ }^{1,2}$ and Andreas Faissner ${ }^{1,2}$ * \\ 1 Department of Cell Morphology and Molecular Neurobiology, Ruhr-University Bochum, Bochum, Germany \\ 2 International Graduate School of Neuroscience, Ruhr-University Bochum, Bochum, Germany
}

\author{
Edited by: \\ Thorsten Doeppner, University of \\ Duisburg-Essen, Germany \\ Reviewed by: \\ Ayman EIAli, CHU de Québec \\ Research Center (CHUL), Canada \\ Luca Peruzzotti-Jametti, University \\ of Cambridge, UK \\ *Correspondence: \\ Andreas Faissner, Department of \\ Cell Morphology and Molecular \\ Neurobiology, Ruhr-University \\ Bochum, Universitätsstraße 150, \\ Bochum 44780, Germany \\ e-mail: andreas.faissner@rub.de
}

The limited regeneration capacity of the adult central nervous system (CNS) requires strategies to improve recovery of patients. In this context, the interaction of endogenous as well as transplanted stem cells with their environment is crucial. An understanding of the molecular mechanisms could help to improve regeneration by targeted manipulation. In the course of reactive gliosis, astrocytes upregulate Glial fibrillary acidic protein (GFAP) and start, in many cases, to proliferate. Beside GFAP, subpopulations of these astroglial cells coexpress neural progenitor markers like Nestin. Although cells express these markers, the proportion of cells that eventually give rise to neurons is limited in many cases in vivo compared to the situation in vitro. In the first section, we present the characteristics of endogenous progenitor-like cells and discuss the differences in their neurogenic potential in vitro and in vivo. As the environment plays an important role for survival, proliferation, migration, and other processes, the second section of the review describes changes in the extracellular matrix (ECM), a complex network that contains numerous signaling molecules. It appears that signals in the damaged CNS lead to an activation and dedifferentiation of astrocytes, but do not effectively promote neuronal differentiation of these cells. Factors that influence stem cells during development are upregulated in the damaged brain as part of an environment resembling a stem cell niche. We give a general description of the ECM composition, with focus on stem cell-associated factors like the glycoprotein Tenascin-C (TN-C). Stem cell transplantation is considered as potential treatment strategy. Interaction of transplanted stem cells with the host environment is critical for the outcome of stem cell-based therapies. Possible mechanisms involving the ECM by which transplanted stem cells might improve recovery are discussed in the last section.

Keywords: brain damage, stem cells, stem cell niche, reactive gliosis, extracellular matrix

\section{INTRODUCTION}

Regeneration of the adult central nervous system (CNS) after damage is limited in mammals. This causes severe problems for patients who suffer from CNS lesions or stroke. Regeneration of the peripheral nervous system is more effective, differences in the cellular response are attributed to this discrepancy (Brosius Lutz and Barres, 2014). Several approaches have been tested in animal models to improve functional recovery of patients, for instance neutralization of inhibitory factors by injection of blocking antibodies or by enzymatic degradation (Zhao et al., 2013). Transplantation of stem cells are another promising strategy and effort is made to examine their effect on regeneration in clinical trials (Savitz et al., 2014). For an efficient treatment, an understanding of the cellular and molecular mechanisms underlying the observed limitations is of interest.

In the first section we describe the effect of CNS damage on astrocytes that become reactive and in many cases start to reexpress neural progenitor markers. The second section is focused on the extracellular matrix (ECM) and factors in this matrix expressed by these astrocytes and other cell types. The third section is dedicated to the question how transplanted stem cells can interact with the host and by which mechanisms they might improve regeneration.

\section{LESIONS OF THE CENTRAL NERVOUS SYSTEM ACTIVATE ENDOGENOUS PROGENITOR-LIKE CELLS}

After stroke or lesion, astrocytes, microglia, and other cell types of the immune system are activated in a process called reactive gliosis (reviewed by Donnelly and Popovich, 2008; Burda and Sofroniew, 2014). Astrocytes change their morphology and subpopulations of them upregulate markers typical of immature neural progenitors during development (Figure 1). In severe cases, a glial scar is formed by astrocytes that intermingle with fibroblasts before they segregate (Bundesen et al., 2003). In the following first section of the review, we want to give a short overview of the markers these astroglial subtypes express, of their spatial distribution and origin, and of the neurogenic potential these cells might have in vivo. 

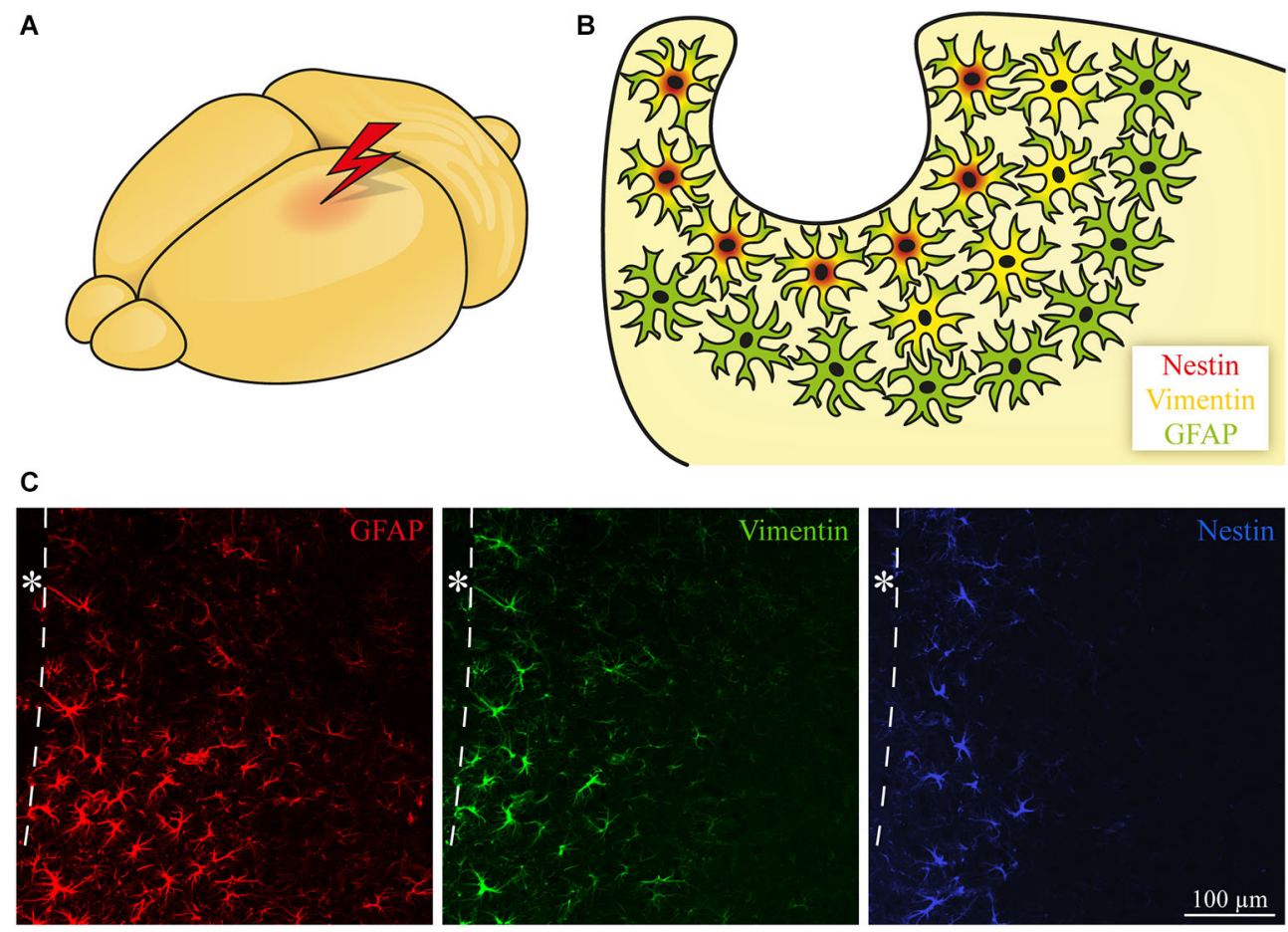

FIGURE 1 | Subtypes of reactive astroglia. (A, B) Astrocytes become reactive following CNS damage. In addition to GFAP upregulation, some of the cells start to express progenitor markers like Vimentin and Nestin The position of the cells in relation to the lesion determines the expression pattern with Nestin near the lesion, Vimentin in a broader area and GFAP with a widespread upregulation. (C)

Immunohistochemical staining of GFAP (red), Vimentin (green), and Nestin (blue, in an adjacent slice) expression after focal laser lesion of the mouse visual cortex. The dashed line depicts the border to the lesion core; * lesion core.

\section{PROGENITOR MARKER EXPRESSION AFTER CNS DAMAGE}

Astrocytes become reactive after CNS damage and typically express the intermediate filament Glial fibrillary acidic protein (GFAP). In addition, other markers like the intermediate filaments Vimentin and Nestin are coexpressed (Pekny and Nilsson, 2005). Vimentin is expressed in radial glia during development (Bignami et al., 1982), whereas Nestin is the prototypical neural stem/progenitor cell marker (Lendahl et al., 1990). Depending on the time point after lesion, additional markers for immature glia like Brain lipid-binding protein (BLBP), the DSD-1 epitope on members of the receptor protein tyrosine phosphatase (RPTP) $\beta$ family, and Tenascin-C (TN-C) are expressed (Robel et al., 2011).

The function of GFAP and Vimentin in regeneration is discussed (Brenner, 2014). For example, knockout mice deficient for GFAP and Vimentin showed reduced hypertrophy of astrocytes, improved synaptic restoration after entorhinal cortex lesion (Wilhelmsson et al., 2004), and supported integration of cells transplanted into the retina (Kinouchi et al., 2003) or into the hippocampus (Widestrand et al., 2007). In contrast, an increased lesion volume was found in GFAP/Vimentin double knockout mice after stroke, whereas single knockouts had no effect on the lesion volume ( $\mathrm{Li}$ et al., 2008). Different GFAP isoforms are described for human and mice, but especially for mice there is no clear correlation of certain isoforms with stem/progenitor cells (Kamphuis et al., 2012). The role of TN-C and other ECM components in regeneration is discussed in the second section.

\section{ASTROGLIAL SUBTYPES ARE ARRANGED IN DISTINCT AREAS}

The different markers mentioned above are not uniformly expressed by all astrocytes. Instead, subpopulations express different combinations. Here it was observed that the cells show a specific spatial distribution. For example, focal laser lesions in the adult mouse visual cortex (Roll et al., 2012) induce GFAP upregulation in a wide area, whereas the progenitor markers Vimentin and even more extremely Nestin are restricted to an area near the lesion core (Figure 1). Interestingly, astrocytes (type B cells) are the stem cells of the subventricular zone (SVZ) and are also positive for Nestin and Vimentin (Doetsch et al., 1997, 1999). Differences in marker expression may reflect the potential of the cells to form other neural cell types. It was described that multipotent neural stem/progenitor cells that give rise to neurons, astrocytes, and oligodendrocytes in vitro appear in the brain following stab wound (Buffo et al., 2008), laser lesion (Sirko et al., 2009), and in other lesion models (Sirko et al., 2013). As shown by differential marker expression, reactive astrocytes are a heterogeneous population with respect to the distance of a cell to the lesion. Additionally, astrocytes are also heterogeneous regarding morphology, function, CNS region, and severity of the lesion (reviewed by Anderson et al., 2014). 


\section{DIFFERENT ORIGINS OF MULTIPOTENT CELLS AFTER CNS DAMAGE}

An obvious question regarding multipotent stem/progenitor cells in the damaged adult brain is the origin of those cells. Are adult stem cells attracted from the stem cells niches like the SVZ and migrate to the lesion site, or are local astrocytes induced to dedifferentiate on-site? An argument for activation of local cells in focal laser lesions of the visual mouse cortex is the distinct spatial distribution of markers like GFAP, Vimentin, and Nestin. A similar finding of Nestin-expressing cells in a distinct pattern was made in the spinal cord after hemitransection and was also interpreted as local activation (Lang et al., 2004). Re-expression of the ECM molecule TN-C, which is expressed during development and later downregulated in the adult cortex, is also restricted to astrocytes located near the lesion (McKeon et al., 1991; Roll et al., 2012). It can be assumed that gradients of signaling molecules with high concentrations near the lesion and decreasing levels in the periphery influence the cell fate and result in the observed regional differences. Indeed, fate mapping studies by Buffo et al. (2008) showed that stab wounds activate local astrocytes in the cortex that are multipotent in vitro. Multipotent cells that give rise to neurons, astrocytes, or oligodendrocytes can be found in the developing nervous system. Different tripotential, but also subtypes of bipotential glial precursors have been described there. For example, glial restricted precursors (GRPs) that produce oligodendrocytes and astrocytes, O2A cells that give rise to oligodendrocytes and type- 2 astrocytes, and others are distinguished according to their potential in vivo and in vitro and to their marker expression (Liu and Rao, 2004). The proteoglycan Neuron-glial antigen 2 (NG2) is associated with glial precursors during development, therefore the contribution of NG2-positive cells present in the adult CNS after damage is discussed (Han et al., 2004; Komitova et al., 2011). In the spinal cord, it has been shown that ependymal cells contribute significantly to newly formed astrocytes and show multilineage potential (Barnabé-Heider et al., 2010). To what extent cells after damage only share similarities or if they acquire a cell fate that is indeed identical to those developmental populations is hard to determine. Depending on the severity, in addition to a local response cells from the adult stem cell niches are activated (Shimada et al., 2010). A stem cell response in terms of an increased SVZ size (Thored et al., 2006) and attraction of neuroblasts from the SVZ to the striatum after stroke was reported (Arvidsson et al., 2002; Yamashita et al., 2006). Regional differences in the potential of SVZ cells are described, such as dorsolateral prevalence of oligodendroglial cells and neuronal and astroglial fates in the ventrolateral area (reviewed by Maki et al., 2013). In some cases, attraction of cells from the SVZ could not be shown by cell tracing experiments (Shimada et al., 2012) or fate mapping (Buffo et al., 2008). In contrast to the described promoting effects of stroke on the adult stem cell niche, chronic inflammation reduces proliferation and impairs migration of neuroblasts (Pluchino et al., 2008). So in general, local activation as well as an influence on the existing adult stem cell niches are conceivable and may take place in parallel. Certainly, this depends on the type, severity, and localization of the damage and further studies are needed to determine the contribution of both mechanisms in different lesion paradigms.

\section{DIFFERENCES OF THE NEUROGENIC POTENTIAL IN VIVO AND IN VITRO}

In many cases, the neurogenic potential of the cells in vivo is more restricted compared to the situation in vitro. So reactive astrocyte-derived cells appear to be multipotent in culture, but fail to form neurons after transplantation in vivo (Shimada et al., 2012). An approach to promote the neuronal fate of reactive astrocytes is retroviral expression of the proneural transcription factor NeuroD1, allowing astrocytes to differentiate into glutamatergic neurons (Guo et al., 2014). Another transcription factor, Sox2, was able to convert spinal cord astrocytes into neurons ( $\mathrm{Su}$ et al., 2014). A further strategy is the administration of neurogenesispromoting factors, as shown for Galectin-1 after stroke (Ishibashi et al., 2007). More strategies have been summarized by Obermair et al. (2008).

The main difference between endogenous stem/progenitor cells in situ and their isolated and cultured counterparts is the completely changed environment, where signals from other cell types are lost. Among them are several neurogenesis-inhibiting factors (Seidenfaden et al., 2006; Buddensiek et al., 2009), one of the candidates is Notch (Aruga et al., 2002). Stress during isolation, high concentrations of growth factors in the medium, and the oxygen and energy supply are additional factors that may influence the cells' potential. This shows that both, multipotent cells combined with a permissive environment, are necessary for the formation of neurons after lesion. The ECM contains a tremendous variety of signaling molecules and with regard to its importance for regeneration it is the topic of the next section.

\section{EXTRACELLULAR SIGNALS INFLUENCE REGENERATION AND STEM/PROGENITOR CELLS}

The ECM is a complex network of interacting molecules that are secreted by the cells into the extracellular space. Depending on the tissue, it functions as a scaffold for the cells and provides mechanical stability, for example in cartilage (Treilleux et al., 1992), but also in all other tissues. The ECM in the CNS is free of fibrillar elements, except after lesion (Heck et al., 2007). It contains glycoproteins like $\mathrm{TN}-\mathrm{C}, \mathrm{TN}-\mathrm{R}$, and proteoglycans (PG; Zimmermann and Dours-Zimmermann, 2008). PGs consist of a core protein and covalently attached carbohydrate (glycosaminoglycan, GAG) chains. Important Chondroitin sulfate proteoglycans (CSPGs) are molecules of the Lectican family and members of the RPTP $\beta$ family, whereas the Heparan sulfate proteoglycans (HSPGs) Syndecan and Glypican are other prominent constituents. Interactions of PGs with other molecules can be mediated by the core protein or by the carbohydrate structures. The ECM is able to bind growth factors and to present them to the cells (Clark, 2008; Brizzi et al., 2012). This allows the extracellular signals to regulate processes like cell survival, proliferation, and differentiation as well as migration or axon growth. According to changing requirements during development, the ECM composition is variable. After CNS lesions, the ECM is altered again. For example, reactive gliosis can lead to a glial scar that has a beneficial effect as it provides a barrier for healthy tissue from the environment (Pekny et al., 2014). At the same time, it is the major obstacle for axonal regrowth (Silver and Miller, 2004; Rolls et al., 2009). But the ECM is more than one constituent of 
the glial scar. It is involved in synaptic plasticity in many ways, for example in long term potentiation (LTP; Dityatev and Schachner, 2003). As mentioned above, the ECM contains signals regulating processes that are critical for regeneration and therefore this second section of the review is dedicated to details regarding the ECM composition and associated factors after CNS damage.

\section{EXTRACELLULAR MATRIX AFTER CNS DAMAGE}

After lesion, several aspects of extracellular signals are critical: (i) barriers like the glial scar are important to protect the healthy tissue from the environment, but they also prevent axonal regrowth or cell migration; (ii) plasticity-limiting factors stabilize neuronal networks in the healthy brain but exacerbate reorganization in case of damage; and (iii) the balance between dedifferentiation and re-differentiation. If cells are induced by the extracellular signals to de-differentiate, but get no signal for proper differentiation, they will stay in an undifferentiated state and cannot replace lost tissue. For example, TN-C, which is also present in the adult stem cell niche, may inhibit differentiation of an astrocyte-derived progenitor cell into a functional neuron or oligodendrocyte. This could be mediated by repression of the RNA-binding molecule Sam68 (Moritz et al., 2008; Czopka et al., 2010).

\section{Extracellular matrix under different pathological conditions}

Changes in the ECM composition differ depending on the type of CNS damage. As a disease-specific description is not the aim of this review, we recommend the following publications: strokeinduced effects were reviewed by Ellison et al. (1999), with focus on the blood-brain barrier by Baeten and Akassoglou (2011). Reports are also available for brain tumors (Gladson, 1999; Wade et al., 2013), spinal cord injuries (Condic and Lemons, 2002), neurodegenerative diseases like Alzheimer's (Morawski et al., 2012), and for autoimmune disorders like multiple sclerosis (Sobel, 1998; van Horssen et al., 2007).

\section{SOURCES OF EXTRACELLULAR MATRIX AND ASSOCIATED SIGNALING MOLECULES}

In response to damage, a number of cell types react and communicate via extracellular signals. The main sources of ECM and related important signaling molecules in the matrix are summarized in this paragraph. Important sources of extracellular molecules are listed in Table $\mathbf{1 .}$

\section{Vasculature}

Blood vessels are an important signal source, as reviewed by Gattazzo et al. (2014). As part of the neurovascular niche they are also thought to be crucial for the residing stem/progenitor cells in the adult stem cell niches (Shen et al., 2008). Endothelial cells produce a number of factors that act on neural cells. Among others, Pleiotrophin, Leukaemia inhibitory factor (LIF), Brainderived neurotrophic factor (BDNF), and Fibroblast growth factor (FGF) 2 influence differentiation (Carmeliet, 2003; Dugas et al., 2008). Vascular endothelial growth factor (VEGF) is an important regulator of angiogenesis and neurogenesis (Jin et al., 2002; Nag et al., 2002). Angiogenesis is increased in the damaged CNS and therefore more cells get in contact with the perivascular
Table 1 | Important sources of extracellular signaling molecules after CNS lesion.

\section{Cell type}

Extracellular matrix-related molecule

Endothelial cells

Brain-derived neurotrophic factor (BDNF)

Fibroblast growth factor 2 (FGF2)

Leukaemia inhibitory factor (LIF)

Pleiotrophin

Vascular endothelial growth factor (VEGF)

Fibrinogen [blood-derived]

$\begin{array}{ll}\text { Pericytes } & \text { Fibronectin } \\ \text { Astrocytes } & \text { Agrin } \\ & \text { Brevican } \\ & \text { Collagen IV, VIII } \\ & \text { Decorin } \\ & \text { Fibronectin } \\ & \text { Glypican } \\ & \text { Laminin } \\ & \text { Neurocan } \\ & \text { Phosphacan } \\ & \text { Syndecan } \\ & \text { Tenascin-C } \\ & \text { Thrombospondin } \\ & \text { Versican } \\ & \text { Matrix metalloproteinase 9 (MMP-9) } \\ & \text { Neurocan } \\ \text { Neuron-glial antigen 2 (NG2) } & \text { Nogo-A } \\ \text { Oligodendrocytes/ } & \text { Versican } \\ \text { Precursors } & \text { Chemokines } \\ & \text { Cytokines } \\ \text { Sonic hedgehog (SHH) } \\ \text { Cytokines } \\ \text { Neuron-glial antigen 2 (NG2) } \\ \text { Neurotrophic factors } \\ \end{array}$

As the origin of secreted molecules is often difficult to determine by immunological studies, more molecules are expressed that have not yet been allocated. References are given in the text.

niche (Arai et al., 2009). Hypoxia supports stemness during development, but also under pathological conditions like stroke (Panchision, 2009). This is mediated by Hypoxia-inducible factor (HIF) I $\alpha$, which facilitates Notch signaling and inhibits factors responsible for differentiation, for example Bone morphogenetic proteins (BMPs). The blood-brain barrier is disrupted in many cases as result of mechanical damage or chemokines (Dimitrijevic et al., 2006), which allows cells like T lymphocytes and additional factors from the blood to enter the CNS that are retained under normal conditions. When Fibrinogen from the blood crosses the disturbed blood-brain barrier, it activates astrocytes by providing Transforming growth factor $\beta$ (TGF- $\beta$; Schachtrup et al., 2010). Pericytes are involved in the production of the glial scar, including Fibronectin (FN; Göritz et al., 2011). In addition, vessels are used as guiding structures by migrating neural progenitors in the healthy and diseased brain (Massouh and Saghatelyan, 2010).

\section{Astrocytes}

Astrocytes are extremely heterogeneous in their expression profile, as described in the first section. Depending on the type of damage, the time point after lesion, and the position, reactive astrocytes are responsible for $\mathrm{TN}-\mathrm{C}$ expression in many lesion 
models (McKeon et al., 1991; Roll et al., 2012) and also express Brevican, Versican (Beggah et al., 2005), Neurocan (Haas et al., 1999), Phosphacan (McKeon et al., 1999), Decorin (Stichel et al., 1995), Laminin, and FN (Gris et al., 2007). HSPGs expressed by reactive astrocytes are Glypican, Syndecan, and Agrin (Iseki et al., 2002; Hagino et al., 2003; Falo et al., 2008). Collagen expression, which is involved in glial scar formation, was also shown for reactive astrocytes. The basement membrane-associated type IV (Liesi and Kauppila, 2002) and type VIII (Hirano et al., 2004) Collagens were detected. Astrocytes are also a source of Thrombospondins (TSPs; Lin et al., 2003) (reviewed by Sofroniew, 2009). Astrocytic expression of TN-C, Neurocan, and Phosphacan is increased by presence of meningeal fibroblasts in vitro (Wanner et al., 2008). Activation of astrocytes is mediated by proinflammatory cytokines like Interleukin (IL)-1 $\beta$, IL-6, and Tumor necrosis factor $\alpha$ (TNF- $\alpha)$. They are secreted by microglia, in part by the astrocytes themselves, or by other cell types (Buffo et al., 2010).

\section{Oligodendrocytes}

Oligodendrocytes produce Nogo-A, an inhibitor of neurite outgrowth (Chen et al., 2000). Oligodendrocyte precursors express the CSPGs Neurocan and NG2 (Levine, 1994; Asher et al., 2000) and oligodendrocyte lineage cells secrete Versican under pathological conditions (Asher et al., 2002). Matrix metalloproteinase 9 (MMP-9) produced by oligodendrocyte precursors leads to blood-brain barrier leakage (Seo et al., 2013).

\section{Neurons}

Neurons start to express numerous chemokines like Chemokine (C-C motif) ligand 20 (CCL20), CCL21, CXC chemokine ligand 12 (CXCL12/SDF-1), and CXCL14/BRAK under pathological conditions (Das et al., 2012). They are primarily involved in immunomodulation, but additional functions as neuromodulators are assumed (Rostène et al., 2011).

\section{Microglia}

Microglia, the macrophages of the CNS, are activated by several mechanisms after injury. For example, they can detect reduced neuronal activity by alterations in neurotransmitter concentration and become activated (Biber et al., 2007; Kettenmann et al., 2011). Chemokines expressed after lesion can induce migration of microglia, for example Cysteine-cysteine (CC) chemokines (Carbonell et al., 2005). The consequence of microglial activation is the upregulation of cytokines and neurotrophic factors (Donnelly and Popovich, 2008). Increased levels of cytokines can induce remodeling of the ECM, for example by inducing the expression of MMPs (Gottschall and Yu, 1995) and of matrix molecules like TN-C by reactive astrocytes. Activated microglia also express ECM molecules themselves, for example NG2 (Sugimoto et al., 2014).

\section{CLASSES OF EXTRACELLULAR MATRIX MOLECULES IN THE POSTLESIONAL CNS}

Important classes of extracellular signaling molecules that are typically present after CNS damage are described below. In many cases, components typical of the stem cell niches are re-expressed and provide an environment that resembles - in part-a neural stem cell niche like the SVZ. That niche is formed by signals from the vasculature, cerebrospinal fluid, and a complex set of extracellular molecules secreted by the cells in the niche (reviewed by Kazanis and ffrench-Constant, 2011). The situation after lesion with upregulated ECM molecules and the niche-like environment is summarized in Figure 2. As described above, major sources of the signals are reactive astrocytes, microglia, and the vasculature. Important functions regulated by ECM molecules and associated factors are listed in Table 2.

\section{Chondroitin sulfate proteoglycans}

CSPGs act as barrier after CNS damage and contribute to the axonal growth-inhibitory environment including the glial scar (Brown et al., 2012). CSPGs are mainly expressed by reactive astrocytes. Their effect can be mediated by members of the Leukocyte common antigen-related (LAR) family of RPTPs that comprises for example LAR, RPTP $\delta$, RPTP $\sigma$, and the Nogo receptors NgR1 and NgR3 (reviewed by Cregg et al., 2014). LARs are involved in $\beta$-Catenin recruitment, leading to changes in the Actin cytoskeleton, which in turn affects axon growth and synaptic organization (Um and Ko, 2013). The Actin cytoskeleton is also targeted by $\mathrm{NgR} 1$ and coreceptors, in this case via the small GTPase RhoA and Rho-associated kinase (ROCK; Fournier et al., 2003; Schwab and Strittmatter, 2014). In addition to the above mentioned receptors, CSPGs can bind to specific receptors like Integrins, a family of heterodimeric transmembrane receptors (see the detailed Integrin description below). CSPGs can also act indirectly, when they intensify growth factor-induced signaling by presenting a growth factor to its receptor, or conversely, block signaling by sequestering growth factors like Pleiotrophin (Deepa et al., 2002) from their receptors (reviewed by Carulli et al., 2005; Sharma et al., 2012b). Neurocan, Brevican, and Versican levels are increased after lesion (Jones et al., 2003; Beggah et al., 2005) as well as Biglycan, Decorin (Stichel et al., 1995), and NG2 (Levine, 1994). NG2 inhibits neurite outgrowth, consequently its neutralization improves recovery (Dou and Levine, 1994; Petrosyan et al., 2013). It is produced by oligodendrocyte progenitors, but not by GFAP-positive astrocytes. This is in line with reports that NG2-positive progenitors are not an important source of astrocytes after brain injury (Komitova et al., 2011). Macrophages and microglia are additional sources of NG2 (Jones et al., 2002; Sugimoto et al., 2014). Decorin antagonizes scar formation as it is able to reduce the expression of Neurocan, Brevican, NG2, and Phosphacan, probably by inhibiting TGF$\beta$ and antagonizing the Epidermal growth factor (EGF) receptor (Davies et al., 2004). The RPTP $\beta$ (or "RPTP $\beta / \zeta$ ") family comprises four isoforms. Alternative splicing of a single gene and proteolytic processing result in two transmembrane receptor forms (RPTP $\beta$ long and RPTP $\beta$ short) and two secreted molecules (Phosphacan and Phosphacan short isoform (PSI; Garwood et al., 2003; Chow et al., 2008)). The receptor forms contain two cytoplasmic tyrosine phosphatase domains, of which only one is catalytically active (Krueger and Saito, 1992). Substrates for this domain are $\beta$-Catenin, which is related to the Actin cytoskeleton and Wnt signaling (Meng et al., 2000), Fyn kinase (Pariser et al., 2005a), and others. Dimerization following 


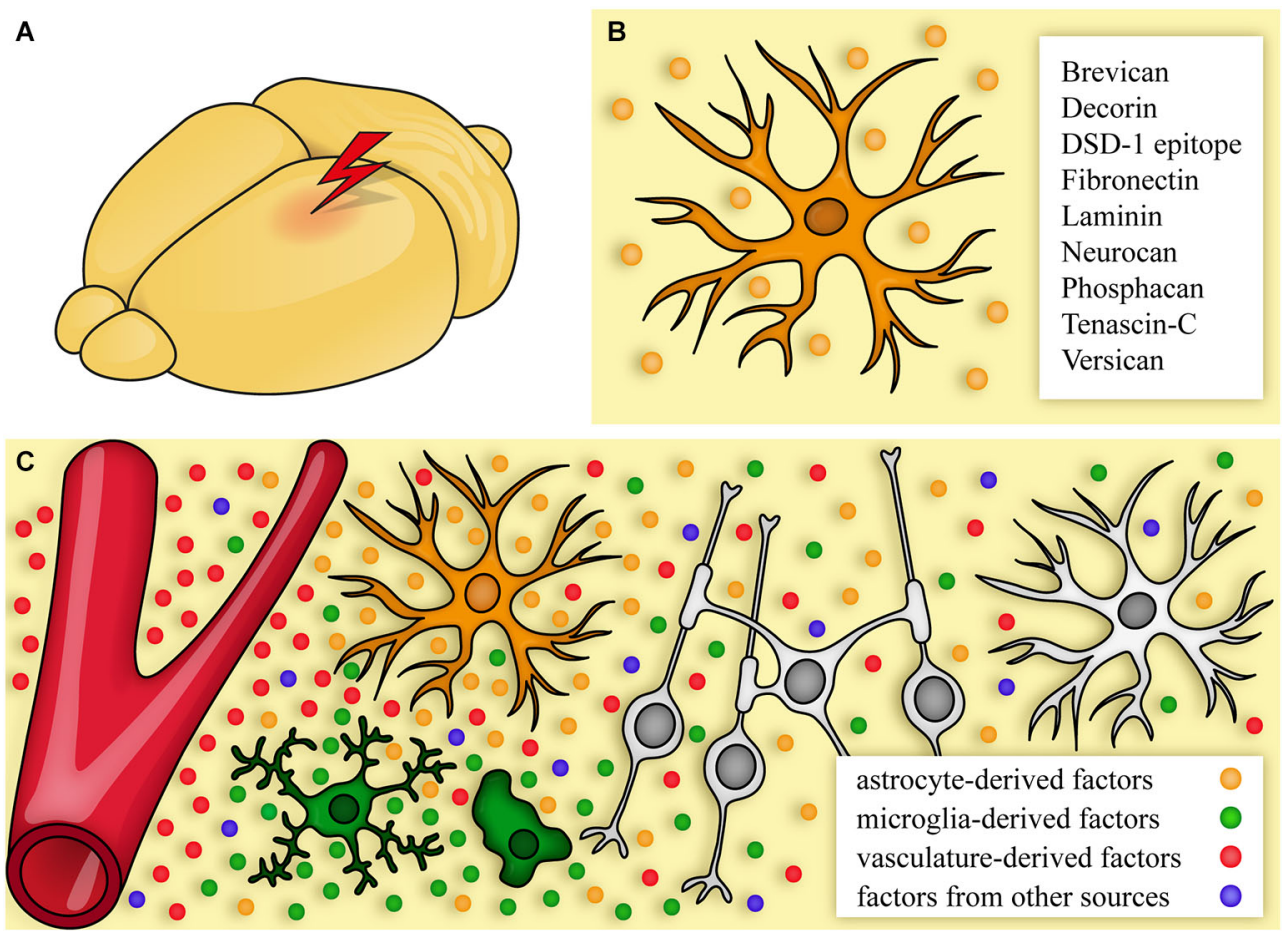

FIGURE 2 | The extracellular matrix after CNS damage. (A, B) After lesion, cells start to produce an altered extracellular matrix (ECM). One major source are reactive astrocytes (B) that express CSPGs and other ECM molecules. (C) Signals come from astrocytes (orange), the vasculature (red), immune cells/microglia (green), and additional sources (blue, for a detailed list see Table 1). This environment can promote, but also inhibit regeneration by affecting neurons, astrocytes, and oligodendrocytes.
Pleiotrophin binding inactivates the phosphatase domains and thereby increases the phosphorylation state of downstream factors like Adducin, a cytoskeletal protein (Pariser et al., 2005b). Other extracellular interaction partners are TN-C, Contactin/F3/F11, the cell adhesion molecules L1CAM and NCAM (Klausmeyer et al., 2007), and FGF (Milev et al., 1998b). RPTP $\beta$ isoforms are regulated after knife lesion of the cerebral cortex (Dobbertin et al., 2003), striatal stab wound (Barker et al., 1996), and after retinal laser lesion (Besser et al., 2009) and are critical for recovery (Harroch et al., 2002). PSI as the smallest member of the RPTP $\beta$ family promotes axon growth (Garwood et al., 2003). Two isoforms (RPTP $\beta$ long and Phosphacan) can be decorated with Chondroitin sulfate GAG chains. These chains regulate the affinity to binding partners, for example to Contactin/F3/F11 (Milev et al., 1998a). A specific Chondroitin sulfate structure, the "DSD-1" epitope, is recognized by the monoclonal antibody 473HD (Faissner et al., 1994; Gates et al., 1995). This epitope is expressed on neural stem cells during development (von Holst et al., 2006) and it has been shown that blocking of this epitope impairs neurosphere formation in vitro. Subpopulations of reactive astrocytes after laser lesion in the visual cortex of rats and mice express the DSD-1 epitope (Sirko et al., 2009; Roll et al., 2012). As mentioned above, this might reflect the immature characteristics of some reactive astrocytes and at the same time a neurogenic niche-like signal after CNS damage.

\section{Collagens}

Collagens comprise 28 members and can be divided into fibril-forming and network-forming Collagens (Ricard-Blum, 2011). In the CNS, Collagens are associated with the vasculature. Integrins are important Collagen receptors: the Integrin subunits $\alpha 1, \alpha 2, \alpha 10, \alpha 11$, and $\beta 1$ interact with different Collagens. Additional receptors are members of the Discoidin domain receptors (DDRs), a subfamily of receptor tyrosine kinases (Leitinger and Hohenester, 2007). In addition to cell adhesion, Collagens are able to activate intracellular pathways and can induce proliferation (Pozzi et al., 1998). Collagens are expressed by astrocytes after lesion. Type IV and type VIII Collagens, both network-forming and associated with the basement membrane, have been found upregulated in the CNS (Liesi and Kauppila, 2002; Hirano et al., 2004). In general, Collagen expression is suppressed via EGF signaling (Heck et al., 2007).

\section{Fibronectin}

FN is a secreted glycoprotein that forms dimers via disulfide bonds near the $\mathrm{C}$ terminus. FN interacts with ECM molecules like Collagens, HSPGs, and TN-C and acts as ligand for Integrin receptors (Singh et al., 2010). FN is expressed by astrocytes and microglia/macrophages after CNS damage, also liver-derived plasma FN has a neuroprotective function in CNS repair (Tate et al., 2007a; Kim et al., 2013). FN activates microglia through 
Table 2 | Parameters modulated by extracellular signals after lesion.

\begin{tabular}{ll}
\hline Parameter & Modulating factor in the extracellular matrix \\
\hline Cell survival, & Neurotrophic factors* \\
proliferation & Cytokines* \\
& Growth factors* \\
Differentiation, & Agrin \\
axon growth, & Brevican \\
synaptic plasticity & Collagen \\
& Decorin \\
& Glypican \\
& Laminin \\
& Neurocan \\
& Neuron-glial antigen 2 (NG2) \\
& Nogo-A \\
& Phosphacan; with attached DSD-1 epitope \\
& Pleiotrophin \\
& Syndecan \\
& Tenascin-C \\
& Tenascin-R \\
& Thrombospondins \\
& Versican \\
CXC chemokine ligand 12 (CXCL12) \\
Fibronectin \\
Laminin \\
Tenascin-C \\
Thrombospondins \\
Migration
\end{tabular}

Many molecules regulate several aspects, only main functions are listed here. References are given in the text.

* signaling is modulated by the extracellular matrix.

binding to Integrin $\alpha 5 \beta 1$ (Milner et al., 2007) and has a neurite growth-promoting effect in vitro (Tom et al., 2004).

\section{Heparan sulfate proteoglycans}

HSPGs are, in contrast to the inhibitory CSPGs, ascribed to the neurite outgrowth-promoting factors (Yamaguchi, 2001). It is assumed that HSPGs can interfere with CSPG signaling by interacting with the same receptors, for example RPTP $\sigma$ (Coles et al., 2011). Accordingly, downstream factors like N-Cadherin (Siu et al., 2007) might be regulated. The HSPG Glypican is expressed by reactive astrocytes (Hagino et al., 2003). It is involved in Hedgehog signaling (Filmus and Capurro, 2014) and as a HSPG it also regulates FGF signaling (Gordon et al., 1989; Rapraeger et al., 1991; Yayon et al., 1991). Syndecan, which is also able to modulate FGF signaling (Filla et al., 1998), is produced by astrocytes after brain injury (Iseki et al., 2002). Important for axonal growth and cell migration could be the interaction of Glypican-1 with repellent Slit proteins (Ronca et al., 2001). Slit is expressed by reactive astrocytes (Hagino et al., 2003), treatment with specific inhibitors of this interaction is owing (Lau and Margolis, 2010). The Drosophila homolog of Syndecan is involved in Slit signaling (Steigemann et al., 2004), suggesting a similar effect in the mammalian CNS. The HSPG Agrin is also expressed by reactive astrocytes. It has functions in the immune system and in neuromuscular synapse formation and may additionally play a role in CNS synapse formation during regeneration (Falo et al., 2008). Perlecan, which is associated with the vascular basement membrane, is a secreted HSPG that is upregulated following damage. After stroke, a neuroprotective effect was shown after administration of Perlecan domain V. An Integrin-mediated upregulation of VEGF in endothelial cells was attributed to the beneficial function (Lee et al., 2011).

\section{Laminins}

Laminins are trimeric glycoproteins and a crucial component of the basement membrane. Different isoforms of $\alpha, \beta$, and $\gamma$ chains are combined to at least 16 Laminins and interaction with other extracellular molecules like Agrin, Collagen IV, Nidogen, and Perlecan leads to formation of complex networks (Domogatskaya et al., 2012). Laminins signal through different Integrins (Belkin and Stepp, 2000) and promote cell adhesion, migration, and axon growth during development (Calof et al., 1994). Laminins are upregulated in the glial scar by astrocytes (Liesi et al., 1984; McKeon et al., 1995) and in vessels after lesion (Tate et al., 2007b; Sarkar et al., 2012). CSPGmediated inhibition of neurite growth in the scar interferes with Laminin-induced promoting effects (McKeon et al., 1995). Migration of activated neural stem cells along vessels after injury seems to involve Laminin (Kokovay et al., 2010). This could be mediated by $\alpha 6 \beta 1$ Integrin, which is a well-known Laminin receptor and is expressed on neural stem cells (Shen et al., 2008).

\section{Tenascins}

The TN family comprises four members in vertebrates, namely TN-C, TN-R, TN-W, and TN-X (Chiquet-Ehrismann et al., 2014). In the nervous system, TN-C and TN-R are expressed (Joester and Faissner, 2001). TN-C is a glycoprotein that is expressed by astrocytes during development and in adult stem cell niches (Garcion et al., 2004; von Holst, 2008). It has a modular structure including EGF-like repeats and, as a result of alternative splicing, a variable number of FN Type III-like domains (Joester and Faissner, 1999, 2001; von Holst et al., 2007). As each domain is responsible for specific interactions with other extracellular molecules, TN-C isoforms have diverse functions. Six TN-C monomers form a hexamer, called "hexabrachion". Expression of different TN-C isoforms is regulated by the transcription factor Pax6 (von Holst et al., 2007). TN-C interacts with CSPGs, for example with Neurocan (Rauch et al., 1997), members of the RPTP $\beta$ family (Barnea et al., 1994), as well as with Integrins (Yokosaki et al., 1998) and Contactin/F3/F11 (Rigato et al., 2002). Via its EGF-like repeats, TN-C also binds to the EGF receptor (Swindle et al., 2001). Interaction of TN$\mathrm{C}$ has been shown for a number of Integrins, including $\alpha v \beta 3$ (Jones and Jones, 2000a). TN-C-induced pathways include RhoA signaling and a Contactin-dependent inhibition of Fyn kinase. A model is proposed where inactive Fyn in turn prevents expression of the splicing factor Sam68 and thereby impairs oligodendrocyte differentiation (Czopka et al., 2010). TN-C blocks FN-dependent cell migration by interacting with Syndecan-4 (Chiquet-Ehrismann and Chiquet, 2003) and regulates axon growth (Faissner, 1997). During development, maintenance of oligodendrocyte precursors (Czopka et al., 2010) and astrocytic 
lineage progression depend on TN-C (Karus et al., 2011). After lesion, TN-C is re-expressed and it contributes to the glial scar as barrier (McKeon et al., 1991; Deckner et al., 2000). TN-C is detected in different regions of the lesioned CNS, for example in the hippocampus (Niquet et al., 1995; Nakic et al., 1996), cerebellum, and cortex (Laywell et al., 1992). TN-C expression was also reported in the human brain after traumatic brain injury (Hausmann and Betz, 2001). TGF- $\beta$ and FGF2 stimulate TN-C expression (Smith and Hale, 1997). After lesion, TNC isoforms containing the FN Type III-like domains B and D are strongly upregulated (Dobbertin et al., 2010). After spinal cord injury, TN-C has a beneficial effect on spinal cord recovery (Chen et al., 2010). An overview of the different functions of TN-C is given by Chiquet-Ehrismann et al. (2014). TN$\mathrm{R}$ has also a modular structure like $\mathrm{TN}-\mathrm{C}$, but forms trimers instead of hexamers (Joester and Faissner, 2001). TN-R interacts with Integrins, for example $\beta 1$ Integrins (Xu et al., 2014), Contactin/F3/F11, Phosphacan (Jones and Jones, 2000a), and Myelin-associated glycoprotein (MAG; Yang et al., 1999). TN$\mathrm{R}$ is expressed after spinal cord injury (Apostolova et al., 2006) and in the lesioned optic nerve by an increased number of cells (Becker et al., 2000). TN-R is part of perineuronal nets (PNNs) that limit synaptic plasticity in the adult. After damage, this property seems to inhibit synaptic remodeling and thereby affects regeneration.

\section{Thrombospondins}

TSPs are secreted glycoproteins that form trimers (members of subgroup A) or pentamers (subgroup B) (Adams and Lawler, 2011). Interaction partners include ECM molecules like Laminins, Collagens, and PGs, growth factors like FGF2, and Integrin receptors that eventually trigger intracellular signaling cascades (Resovi et al., 2014). Thrombospondins are also involved in Notch signaling, which regulates astrocytic differentiation after lesion (Benner et al., 2013). TSPs are expressed by reactive astrocytes and microglia (Möller et al., 1996; Lin et al., 2003), for example they are upregulated after spinal cord injury (Wang et al., 2009b). TSPs are involved in oligodendrocyte precursor migration (Scott-Drew and ffrench-Constant, 1997), synapse formation (Christopherson et al., 2005), and angiogenesis inhibition (Armstrong and Bornstein, 2003).

\section{Cell adhesion molecules}

Cell adhesion molecules of the Immunoglobulin superfamily (IgSF CAMs) are membrane-bound receptors that mediate contact to the ECM and cell-cell interactions. Axon guidance is one important function of CAMs. Among them, Neural CAM (NCAM) is upregulated after CNS lesion and promotes spinal cord recovery (Zhang et al., 2010). Accordingly, recovery in NCAM knockout mice is affected. The polysialylated form of NCAM (PSA-NCAM) is associated with plasticity and is expressed during development, in the adult stem cell niche, and after CNS damage (Emery et al., 2003). NCAM can modulate GDNF and BDNF signaling (Vutskits et al., 2001; Nielsen et al., 2009) and interacts with the CSPG Neurocan (Friedlander et al., 1994). NCAM can activate a number of intracellular cascades, for example the mitogen-activated protein
(MAP) kinase pathway via a complex of Spectrin, RPTP $\alpha$, Fyn kinase and Focal adhesion kinase (FAK; Budinich et al., 2012). L1CAM, another member of IgSF CAMs, is also an important regulator of axon growth during development. It is again upregulated after lesions, where it limits corticospinal tract sprouting (Jakeman et al., 2006). L1CAM activates, in part together with Integrins, MAP kinase signaling via Src kinase and Phosphoinositide 3-kinase (PI3K). It also modulates the Actin cytoskeleton through Ankyrin and Spectrin and can recruit microtubules via Doublecortin (Maness and Schachner, 2007).

\section{Integrins}

Integrins, a group of heterodimer transmembrane receptors for ECM molecules, are involved in cell adhesion, axon growth, and numerous other processes. Each Integrin heterodimer consists of one $\alpha$ and one $\beta$ subunit. Eighteen $\alpha$ and eight $\beta$ subunits are described, leading to 24 confirmed Integrin heterodimers. Integrins connect ECM and the cytoskeleton via adapters like Talin and activate intracellular pathways that regulate gene expression. The classical downstream cascade of Integrins leads to activation of FAK and subsequent activation of Akt and MAP kinases (Guan, 1997; Guo and Giancotti, 2004). A FAK-independent activation of Src kinase also exists (Arias-Salgado et al., 2003). Some Integrins, including the subunits $\alpha \mathrm{v}, \beta 1, \beta 4$, and $\beta 7$, can crosstalk with growth factor receptors like EGFR (Brizzi et al., 2012). The $\beta 1$ subunit is important in stem cell biology (Campos, 2005). As already mentioned, Integrins bind a huge number of ECM molecules. For example, Integrin $\alpha 6 \beta 1$ binds Laminin (Shen et al., 2008) and $\alpha \mathrm{v} \beta 3$ binds TN-C (Jones and Jones, 2000b). In addition to these outside-in signaling pathways, Integrins can transduce inside-out signals. They are mediated by the cytoskeletal protein Talin and increase the affinity of Integrin for extracellular ligands (Anthis et al., 2009). Like their ligands, Integrins are regulated under pathological conditions and contribute to postlesional changes (Ellison et al., 1999).

\section{Matrix metalloproteinases}

MMPs are able to modulate the ECM by specific proteolytic cleavage (Candelario-Jalil et al., 2009). This function is important in the damaged CNS when the cells' environment needs to be adjusted, for example to increase plasticity. MMP upregulation following injury is described for blood vessels, astrocytes, and microglia (Noble et al., 2002). MMPs degrade defined matrix components. So different TN-C isoforms are cleaved by specific MMPs (Siri et al., 1995), MMP-3 degrades the CSPGs Neurocan, Brevican, and Phosphacan (Muir et al., 2002). Effects of MMPs on regeneration have been described, for example of MMP-9 (Hsu et al., 2008). Here, migration of MMP-9-deficient astrocytes was reduced in vitro. MMP-9 is also involved in blood-brain barrier opening in the diseased CNS (Seo et al., 2013). The expression of MMPs in astrocytes can be regulated by the cytokines IL-1 and TNF- $\alpha$ (Gottschall and Yu, 1995). But not only migration is affected by MMPs: MMP-3 and MMP-9 play a role in neuronal differentiation in response to cytokines in vitro (Barkho et al., 2008). 


\section{Perineuronal nets}

A specialized form of ECM are PNNs. They consist of Hyaluronan, TN-R, the CSPGs Aggrecan, Neurocan, and Brevican, and link proteins (Faissner et al., 2010; Ye and Miao, 2013). PNNs surround subpopulations of neurons, mostly Parvalbumin-positive GABAergic inhibitory interneurons, and are thought to stabilize synapses. Therefore their appearance is correlated with the end of a critical period during development. It has been shown that astrocytes play an important role in PNN formation, as they secrete components of the PNNs (Pyka et al., 2011). In line with this, the quadruple knockout of TN-C, TN-R, Neurocan, and Brevican either in astrocytes or hippocampal neurons leads to reduced PNN formation, accompanied by impaired synaptogenesis, synapse stability, and altered synaptic activity in vitro (Geissler et al., 2013). PNN degradation with the bacterial enzyme Chondroitinase $A B C$ restored synaptic plasticity in the visual cortex after the critical period (Pizzorusso et al., 2002). Although single components like Neurocan can be upregulated after damage (Kwok et al., 2011), reduction of PNNs has been described, which is in line with the fact that plasticity is increased under this condition (Karetko-Sysa et al., 2011). This shows that not only the presence of molecules as such is important, but also the spatial distribution and the interaction of different factors.

\section{GROWTH FACTORS AND OTHER SIGNALING MOLECULES IN THE MATRIX \\ Ephrins and Eph receptors}

Ephrins and their counterparts, the Eph receptors, are potent regulators of neurite growth, as they are able to induce growth cone collapse. Activation of an Eph receptor tyrosine kinase following Ephrin binding leads to RhoA- and ROCK-induced changes of the Actin cytoskeleton (Wahl et al., 2000). Also bidirectional signaling is described, in this case Ephrins can activate RhoA and other pathways (Daar, 2012). Many Ephrins and Eph receptors are upregulated after CNS damage, as reviewed by Goldshmit et al. (2006). Ephrin-B2 and Eph-B2 seem to be involved in segregating invading fibroblasts at the glial scar (Bundesen et al., 2003).

\section{Nogo-A}

Nogo-A is a potent inhibitor of neurite outgrowth and interacts with a complex of receptors, including NgR1, that results in activation of ROCK signaling (reviewed by Schmandke et al., 2014). Nogo-A is produced by oligodendrocytes and is part of the myelin in the CNS. It is one important inhibitor of axonal regeneration (Chen et al., 2000). Interestingly, Nogo-A and NgR1 are also involved in the homeostasis of the adult SVZ. Here, proliferation and differentiation of neural stem cells are restricted by Nogo-A-expressing neuroblasts via NgR1. In addition, neuroblast migration is regulated by Nogo-A in an NgR1-independent mechanism that acts on ROCK (Rolando et al., 2012). Nogo-A and its receptor have been a target for several blocking experiments after stroke (Lee et al., 2004), spinal cord injury (Liebscher et al., 2005), and in other lesion models that showed beneficial effects of Nogo-A inactivation (reviewed by Overman and Carmichael, 2014; Schwab and Strittmatter, 2014). In intact animals, NogoA blocking showed no obvious side effects on cognitive function
(Craveiro et al., 2013), although the Nogo-A receptor NgR1 is involved in memory formation (Karlén et al., 2009) and mice with downregulated Nogo-A show subtle cognitive deficits (Petrasek et al., 2014).

\section{Semaphorins}

Twenty Semaphorins are found in vertebrates, all of them contain a characteristic extracellular Sema domain. The most prominent function of Semaphorins is the regulation of axon growth and their ability to induce growth cone collapse. Semaphorins bind to Plexin and Neuropilin receptors. Different intracellular cascades eventually affect the cytoskeleton and, in many cases, induce growth cone collapse. Microtubule and Actin filament stability can be modified as well as gene expression (Neufeld and Kessler, 2008), pathways that depend on protein synthesis and independent mechanisms coexist (Manns et al., 2012). Sema3A is expressed by fibroblast-like cells after CNS injury (Pasterkamp et al., 1999) and in line with this, meningeal fibroblasts inhibit neurite outgrowth in vitro (Niclou et al., 2003). After optic nerve crush, short-term Sema3A upregulation was observed, whereas other class 3 Semaphorins were upregulated for days (Sharma et al., 2012a). L1CAMFc chimeric molecules can reverse the repellent effect of Sema3A, which shows that the combination of different factors is important rather than a single factor (Castellani et al., 2000).

\section{Sonic hedgehog}

Sonic hedgehog $(\mathrm{SHH})$ is a signaling molecule that is able to regulate gene expression as well as the cytoskeleton. During development, it serves as morphogen and is involved in dorsoventral patterning. Binding of $\mathrm{SHH}$ to its receptor Patched relieves the repression of the seven-transmembrane receptor Smoothened. As a consequence, Gli transcription factors are activated and accumulate in the nucleus. This results in repression or activation of other transcription factors and altered gene expression (Fuccillo et al., 2006). Via a Gli-independent mechanism that involves a guanine nucleotide exchange factor (Tiam1) for the GTPase Racl, SHH acts on the cytoskeleton during dendritic spine formation (Sasaki et al., 2010). SHH is secreted by neurons, endothelial cells (Sirko et al., 2013), and also by reactive astrocytes (Amankulor et al., 2009). This upregulation can only be observed under certain pathological conditions in the CNS. The expression differs depending on the type of damage. So it is detected after stab wound and stroke, but not in a murine Alzheimer's model (Sirko et al., 2013). In this study, it was shown that SHH expression is necessary for multipotency of endogenous neural stem/progenitor cells. The HSPG Glypican, itself upregulated after damage, is involved in Hedgehog signaling (Filmus and Capurro, 2014).

\section{Wnts}

Secreted Wnt proteins influence gene expression and the cytoskeleton. The canonical Wnt pathway starts with binding of Wnt to Frizzled receptor and to the coreceptor LRP. Subsequently, a $\beta$-Catenin-degrading complex is inactivated and $\beta$-Catenin accumulates in the cell. It enters the nucleus, where it interacts with transcription factors and activates Wnt target genes (Reya 
and Clevers, 2005). Non-canonical Wnt pathways also affect the cytoskeleton (Semenov et al., 2007). Wnt proteins are upregulated after lesion and influence regeneration in different ways. It was shown that repulsive Wnts inhibit axonal growth in the spinal cord (Liu et al., 2008), on the other hand Wnt signaling is involved in symmetrical cell division of SVZ cells after stroke (Piccin and Morshead, 2011).

\section{Notch}

Notch is a transmembrane receptor that plays an important role in neural cell fate determination. After binding of its ligand, Jagged or Delta-like, the Notch intracellular domain (NICD) is cleaved by $\gamma$-Secretase. NICD translocates to the nucleus, where it interacts with transcription factors and allows target gene expression (Kopan and Ilagan, 2009). Notch is upregulated and activated after CNS lesion or stroke (Yamamoto et al., 2001; Xiao et al., 2009). Notch and its interaction with TSP 4 after cortical lesion are necessary for the differentiation of SVZ-derived astrocytes (Givogri et al., 2006; Benner et al., 2013). In another study, astrogliosis was promoted by the Notch ligand Jagged, produced by transplanted endothelial progenitor cells (Kamei et al., 2012).

\section{Cytokines}

Cytokines induce diverse cellular responses by activation of specific receptors. Examples for signaling cascades are reviewed by Leonard and Lin (2000) and Schlessinger and Ullrich (1992). Important cytokines expressed by activated microglia and macrophages are Interleukin-1 (IL-1), IL-6, Interferon, and TNF- $\alpha$ (Smith and Hale, 1997). TGF- $\beta$ is increased in microglia under pathological conditions in the brain (Morgan et al., 1993) and the spinal cord (McTigue et al., 2000). They influence the expression levels of MMPs (see above) and activate astrocytes, IL-6 for example promotes EGF-induced astrocyte proliferation (Levison et al., 2000). Astrocytes are another major cytokine source (reviewed by Eddleston and Mucke, 1993; Wiese et al., 2012). BMPs and their inhibitor Noggin regulate neurogenesis in the adult stem cell niche (Lim et al., 2000). BMPs and Noggin are upregulated after brain and spinal cord injury (Hampton et al., 2007) and regulate astrocytic vs. neuronal and oligodendrocytic differentiation (Xiao et al., 2010). By driving the differentiation of astrocytes and CSPG production, BMPs are involved in glial scar formation (Fuller et al., 2007).

\section{Neurotrophic factors}

Neurotrophic factors and growth factors signal via specific transmembrane receptors. Depending on the class of growth factors, receptor tyrosine kinases (e.g., EGF receptor) or serine/threonine receptor kinases (e.g., TGF $\beta$ receptor) induce intracellular signaling cascades (Schlessinger and Ullrich, 1992). Neurotrophins like NT3 bind to Trk (Tropomyosin-related kinase) receptors (Hetman and Xia, 2000). Neurotrophic factors expressed by activated microglia and macrophages are BDNF, Ciliary neurotrophic factor (CNTF), Glial cell line-derived neurotrophic factor (GDNF), Hepatocyte growth factor (HGF), Insulin-like growth factor (IGF), Nerve growth factor (NGF), Neurotrophin (NT)-3 and Platelet-derived growth factor (PDGF; reviewed by Donnelly and Popovich, 2008). Microglia-produced neurotrophic factors can act in an autocrine way, for example BDNF and NT-3 increase microglia proliferation (Elkabes et al., 1996). In the adult spinal cord, high levels of CNTF are expressed following injury (Nakamura and Bregman, 2001). VEGF is secreted by endothelial cells and after damage also by astrocytes (Nag et al., 2002). It increases neurogenesis and plasticity (Jin et al., 2002; Licht et al., 2011). FGF and EGF increase levels of TGF- $\beta$ (Lindholm et al., 1992), which is responsible for astrocyte activation and Neurocan expression (Asher et al., 2000). TGF- $\beta$ increases NGF levels (Lindholm et al., 1990). NGF in turn induces microglial migration via the TrkA receptor, when combined with low concentrations of TGF- $\beta$ (De Simone et al., 2007).

\section{Chemokines}

Chemokines are secreted signaling molecules that bind to $G$ protein-coupled, seven-transmembrane receptors (Salanga et al., 2009). Activation of a receptor induces a cascade including second messengers like cAMP or $\mathrm{IP}_{3}$ that can mediate diverse cellular responses (Patel et al., 2013). The chemokine stromalderived factor 1 (SDF-1/CXCL12) is expressed by astrocytes after stroke and mediates attraction of cells by binding to its receptor, CXCR4. This system is involved in attraction of bone marrow stem cells (Hill et al., 2004), transplanted umbilical cord blood cells (Rosenkranz et al., 2010), and neural stem cells (Imitola et al., 2004). Two isoforms, SDF-1 $\alpha$ and SDF-1 $\beta$, have distinct expression patterns in the lesioned CNS. Neurons express SDF- $1 \alpha$, whereas SDF- $1 \beta$ is expressed by endothelial cells (Stumm et al., 2002). Hence, a dual function of SDF-1-mediated modulation of the immune response and neurotransmission is discussed.

\section{REGENERATION IN ECM KNOCKOUT (KO) MODELS}

The effect of ECM molecules on regeneration was examined in different knockout models. Double knockout of Neurocan and Brevican in mice does not obviously affect recovery after spinal cord injury (Quaglia et al., 2008). In a more sophisticated model with an additional priming lesion in the sensory nerve 7 days after spinal cord injury, only in $\mathrm{KO}$ animals axons crossed the dorsal root entry zone. This uncovered the growth-inhibiting effect of Neurocan and Brevican in the wild-type situation. TN$\mathrm{C} \mathrm{KO}$ mice have a mild phenotype, but recover worse after spinal cord injury (Chen et al., 2010). In contrast, deficiency of TN-R improves functional recovery of mice after spinal cord injury (Apostolova et al., 2006). TN-R seems to restrict synaptic reorganization after injury, which is in line with the role of TN-R in PNNs. EphA4 KO mice exhibit reduced gliosis and improved functional recovery after spinal cord injury (Goldshmit et al., 2004). Therefore, EphA4 seems to regulate two important aspects in regeneration.

\section{EXTRACELLULAR MATRIX AS TARGET FOR IMPROVED RECOVERY}

Inhibitory matrix was the target of different approaches so far, a number of studies have been reviewed by Soleman et al. (2013). The function can be blocked with antibodies, specific inhibitors, by knockdown, or already synthetized ECM can proteolytically be degraded, for example by ADAM proteases (reviewed by Burnside and Bradbury, 2014). Inhibition 
of proteoglycan synthesis by $\beta$-D-Xylosides and sodium chlorate eliminates the inhibitory effect of astrocytic matrix on neurite growth in vitro (Smith-Thomas et al., 1995). Treatment with the Chondroitin sulfate-degrading enzyme Chondroitinase ABC (ChABC) revealed a recovery-promoting effect after spinal cord injury (Bradbury et al., 2002) and had neuroprotective effects (Chen et al., 2014). Although ChABC treatment is effective in many cases, ChABC-resistant inhibitory matrix also remains (Siddiqui et al., 2009) that needs to be addressed by other strategies. These inhibitory signals can be ascribed to the core protein part of PGs or to other molecules in the matrix. Treatment with antibodies directed against an extracellular factor relies on blocking its function. Studies using antibodies against Nogo-A (Zhao et al., 2013) and TN-R (You et al., 2012) have shown improved recovery from spinal cord injury. In addition to the aforementioned strategies that rely on the elimination of ECM function, delivery of regeneration-promoting ECM-related molecules is possible. For example, transplantation of L1CAMoverexpressing neural aggregates improved regeneration more effectively than those with normal L1CAM expression levels (Cui et al., 2011).
Possible mechanisms by which transplanted stem cells can promote regeneration in the context of ECM are discussed in the following third section.

\section{POTENTIAL EFFECTS OF ENDOGENOUS AND TRANSPLANTED STEM CELLS ON REGENERATION}

As described in the first section, endogenous progenitor-like cells appear in the damaged CNS. If a subset of astroglial cells starts to de-differentiate anyway, what could be the benefit of additional, transplanted stem cells? It is clear that in many cases positive effects are not due to cell replacement (Chopp et al., 2009). The last section of this review gives an overview of the different strategies behind stem cell therapies.

What are potential mechanisms by which transplanted stem cells support regeneration? Several strategies to improve recovery have been pursued so far (Burda and Sofroniew, 2014). Roughly the effects can be divided into three main aspects: (i) immune modulation; (ii) support of cell survival, differentiation, or axonal growth; and (iii) cell replacement (summarized in Figure 3A). Examples for factors that are produced by stem cells and their

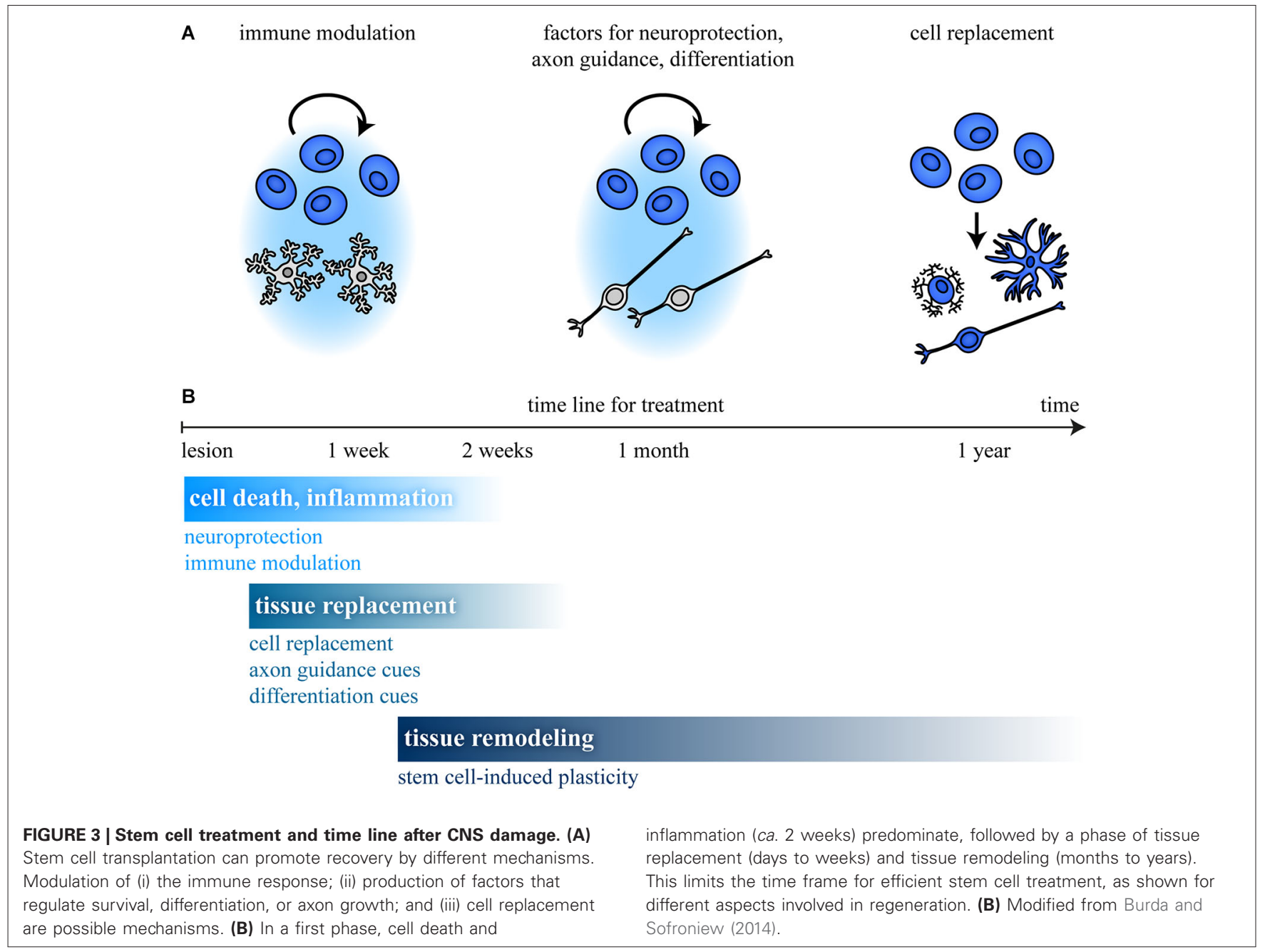


Table 3 | Aspects potentially influenced by transplanted stem cells.

\begin{tabular}{|c|c|}
\hline Parameter & Stem cell-released factor \\
\hline \multirow[t]{3}{*}{ Immune system modulation } & Chondroitin sulfate proteoglycans (CSPGs) \\
\hline & Prostaglandin $\mathrm{E}$ \\
\hline & Tenascin-C \\
\hline \multirow[t]{3}{*}{ Neuroprotection } & Glial cell line-derived neurotrophic \\
\hline & factor (GDNF) \\
\hline & Nerve growth factor (NGF) \\
\hline \multirow{5}{*}{$\begin{array}{l}\text { Axon growth, } \\
\text { differentiation, } \\
\text { synaptic plasticity }\end{array}$} & Matrix metalloproteinases (MMPs) \\
\hline & Neurocan \\
\hline & Phosphacan; with attached DSD-1 epitope \\
\hline & Tenascin-C \\
\hline & Tissue inhibitors of metalloproteinase \\
\hline
\end{tabular}

References are given in the text.

potential effects on regeneration are listed in Table 3. With regard to the phases of regeneration, where a first phase of cell death and inflammation ( $c a .2$ weeks) is followed by a phase of tissue replacement (days to weeks) and finally by tissue remodeling (months to years), at each time point different mechanisms have priority. This limits the time frame for efficient stem cell treatment (Figure 3B). Depending on the desired effect, stem cells of different origin and of different potential are the first choice.

The following aspects may account for differences of cultured and transplanted cells in comparison to the endogenous stem/progenitor pool: (i) the cell number of stem/progenitor cells may be higher when additional cells are transplanted; (ii) the potential of the cultured cells may differ from their endogenous counterparts due to the treatment (stress, addition of factors to the medium, etc.); (iii) not only the potential to differentiate may be changed during culture, but also the factors these cells secrete could differ depending on the pretreatment, the origin, or the differentiation state; (iv) transplantation of stem cells could modulate the immune system and therefore act indirectly on the CNS; and (v) stem cells can also be used as vehicle: for example, genetically modified stem cells stably deliver neurotrophic or other factors to damaged tissue, e.g., CNTF (Jung et al., 2013).

\section{INTERACTION OF STEM CELLS AND THE IMMUNE SYSTEM}

Immune cells can have both, positive and detrimental effects on regeneration, but also on the fate of endogenous and transplanted stem cells (reviewed by Martino et al., 2011; Kokaia et al., 2012). On the other hand, stem cells can modulate the immune response. For example, it has been shown that neurospherederived multipotent progenitors have a neuroprotective effect by immune modulation (Pluchino et al., 2005). Systemically transplanted NSCs improved recovery in a stroke model and reduced the expression of inflammation-associated genes (Bacigaluppi et al., 2009). Stem cells can also suppress T lymphocytes via increased nitric oxide and Prostaglandin E levels (Wang et al., 2009a).

In addition to the typical immune modulators mentioned above, molecules of the ECM can also influence the immune system: CSPGs do not only regulate axon growth, they are also able to modulate the immune response by binding to cytokines and Cluster of differentiation 44 (CD44; reviewed by HaylockJacobs et al., 2011). TN-C, a glycoprotein that is secreted by neural stem/progenitor cells in vitro (von Holst et al., 2007), can influence the immune system via Toll-like receptor (TLR) 4 (Midwood et al., 2009). TN-C and the immune system influence each other reciprocally: TN-C modulates the immune response, but is itself regulated by cytokines during inflammation. A detailed description is given in the review by Jakovcevski et al. (2013). Not only neural stem/progenitor cells can be utilized to improve recovery. For example, bone marrow stromal cells/mesenchymal stem cells (MSCs) reduce microglial activation (Yan et al., 2013). In addition to secreted factors, in the last years the role of exosomes in intercellular communication is being discussed (Ludwig and Giebel, 2012). These small vesicles loaded with lipids, proteins, and RNAs are released by MSCs and other cell types and might represent a mechanism by which transplanted cells can influence the immune system (Kordelas et al., 2014).

\section{PRODUCTION OF NEUROTROPHIC FACTORS AND REGULATION OF PLASTICITY}

As described, stem cells can support neuronal survival by modulating the immune response, but they can also have a direct neuroprotective effect. Stem cells produce neurotrophic factors like GDNF and NGF (Lladó et al., 2004). Furthermore, they express a number of ECM molecules that are present in the developing nervous system. Among them are CSPGs like Neurocan, Phosphacan carrying the DSD-1 epitope (Ida et al., 2006; von Holst et al., 2006) and, as already mentioned, the glycoprotein TN-C. Some of these factors are well-known for their impact on cell differentiation, migration, and axon growth. If these factors are able to influence regeneration after transplantation will mostly depend on the number of surviving cells. A positive effect of human neural progenitor cells on axonal transport and plasticity after stroke was in part attributed to VEGF, TSP and Slit expression (Andres et al., 2011). Transplanted cells that express MMPs or they counterparts, the Tissue inhibitors of metalloproteinases (TIMPs), can control the ECM composition. Also non-neural cells can affect plasticity. So expression of MMPs and TIMPs was shown in MSCs, with differences in the expression profile depending on the origin of the cells (Lozito et al., 2014). MSCs induce SHH expression in host astrocytes that increases plasticity in conjunction with tissue-type plasminogen activator (tPA; Samson and Medcalf, 2006; Ding et al., 2013).

Plasticity can be induced not only on the molecular level. Neural precursors transplanted into the visual cortex differentiated into inhibitory neurons and formed synapses to host cortical neurons, thereby promoting plasticity after the critical period (Southwell et al., 2010).

\section{NEURAL DIFFERENTIATION AND CELL REPLACEMENT BY TRANSPLANTED STEM CELLS}

Embryonic stem (ES) cells provide a source for the different cell types, because as pluripotent cells they can give rise to all cell types of the body, including neurons, astrocytes, and oligodendrocytes 
(Fraichard et al., 1995). To avoid the ethically problematic use of the embryo-derived ES cells, alternative sources for pluripotent cells were investigated. A promising alternative was described in 2006, when fibroblasts were reprogrammed to induced pluripotent stem cells (iPSCs; Takahashi and Yamanaka, 2006). The "Yamanaka cocktail" contains the four factors Oct3/4, Sox2, cMyc, and Klf4. Subsequently, the number of factors could be reduced to two when adult neural stem cells were reprogrammed to iPSCs (Kim et al., 2008). Meanwhile, direct conversion of fibroblasts to induced neural stem cells (iNSCs) without a pluripotent state has been described (Han et al., 2012; Thier et al., 2012), reducing the risk of tumor induction by undifferentiated cells.

Cell fate decisions can be regulated, so astrocytic differentiation of transplanted NSCs is reduced when the CNTF is neutralized (Ishii et al., 2006). Astrocytes can be driven to a glutamatergic, NG2 glia to a glutamatergic and GABAergic neuronal cell fate by retroviral expression of the transcription factor NeuroD1 (Guo et al., 2014). Procedures for the directed differentiation into distinct neuronal subtypes exist, where cells are exposed to defined soluble and surface-bound factors. For example, glutamatergic (Zeng et al., 2010) and GABAergic (Maroof et al., 2013) neurons can be derived from ESCs or iPSCs. Also regional identities like retinal progenitors (Lamba et al., 2006) and subsequently photoreceptors can be produced (Lamba et al., 2010). But not only neurons, also oligodendrocytes as the myelinating cells of the CNS are important for regeneration and protocols are described that promote this cell fate (Neman and de Vellis, 2012). Functional integration of such cells was already shown, also for human cells (Tornero et al., 2013). A combined approach of stem cell-based treatment and manipulation of the ECM is the injection of neural stem cells with Chondroitinase ABC into the lesioned spinal cord (Ikegami et al., 2005). Axonal regrowth was significantly increased by the combined application.

\section{SUMMARY/OUTLOOK}

As shown in this review, the CNS reacts to damage by upregulation of numerous extracellular signaling molecules that in part resemble the neurogenic stem cell niche. In line with this, endogenous stem/progenitor-like cells can be observed in many lesion models. The ECM contains important regulators of cell survival, differentiation, migration, or neurite outgrowth and is able to modulate signaling of associated molecules, for example of growth factors. These signals and the intrinsic properties of the cells present in the lesioned CNS are responsible for the outcome after regeneration. Stem cell transplantation now aims to influence this system or to add cells that replace lost tissue to a certain degree. Some approaches exploit neuroprotective effects by the stem cells, whereas others depend on cell replacement after differentiation and functional integration of the cells. The latter requires a carefully orchestrated sequence of complex actions and therefore seems to be harder to achieve. Stem cell transplantation experiments in animals will help to learn more about the molecular mechanisms that influence regeneration, as they allow to manipulate specific aspects in this complex interplay.

\section{ACKNOWLEDGMENTS}

We thank the International Graduate School of Neuroscience (IGSN), the RUB Research School of the Ruhr-University Bochum, and the German Research Foundation (DFG SFB 509, Fa 159/16-1) for financial support. In particular, we want to thank Prof. Dr. Ulf T. Eysel for performing the laser lesions in the mouse visual cortex (Figure 1).

\section{REFERENCES}

Adams, J. C., and Lawler, J. (2011). The thrombospondins. Cold Spring Harb. Perspect. Biol. 3:a009712. doi: 10.1101/cshperspect.a009712

Amankulor, N. M., Hambardzumyan, D., Pyonteck, S. M., Becher, O. J., Joyce, J. A., and Holland, E. C. (2009). Sonic hedgehog pathway activation is induced by acute brain injury and regulated by injury-related inflammation. J. Neurosci. 29 , 10299-10308. doi: 10.1523/jneurosci.2500-09.2009

Anderson, M. A., Ao, Y., and Sofroniew, M. V. (2014). Heterogeneity of reactive astrocytes. Neurosci. Lett. 565C, 23-29. doi: 10.1016/j.neulet.2013.12.030

Andres, R. H., Horie, N., Slikker, W., Keren-Gill, H., Zhan, K., Sun, G., et al. (2011). Human neural stem cells enhance structural plasticity and axonal transport in the ischaemic brain. Brain 134, 1777-1789. doi: 10.1093/brain/ awr094

Anthis, N. J., Wegener, K. L., Ye, F., Kim, C., Goult, B. T., Lowe, E. D., et al. (2009). The structure of an integrin/talin complex reveals the basis of inside-out signal transduction. EMBO J. 28, 3623-3632. doi: 10.1038/emboj.2009.287

Apostolova, I., Irintchev, A., and Schachner, M. (2006). Tenascin-R restricts posttraumatic remodeling of motoneuron innervation and functional recovery after spinal cord injury in adult mice. J. Neurosci. 26, 7849-7859. doi: 10. 1523/jneurosci.1526-06.2006

Arai, K., Jin, G., Navaratna, D., and Lo, E. H. (2009). Brain angiogenesis in developmental and pathological processes: neurovascular injury and angiogenic recovery after stroke. FEBS J. 276, 4644-4652. doi: 10.1111/j.1742-4658.2009. 07176.x

Arias-Salgado, E. G., Lizano, S., Sarkar, S., Brugge, J. S., Ginsberg, M. H., and Shattil, S. J. (2003). Src kinase activation by direct interaction with the integrin beta cytoplasmic domain. Proc. Natl. Acad. Sci. US A 100, 13298-13302. doi: 10. 1073/pnas.2336149100

Armstrong, L. C., and Bornstein, P. (2003). Thrombospondins 1 and 2 function as inhibitors of angiogenesis. Matrix Biol. 22, 63-71. doi: 10.1016/s0945053x (03)00005-2

Aruga, J., Tohmonda, T., Homma, S., and Mikoshiba, K. (2002). Zicl promotes the expansion of dorsal neural progenitors in spinal cord by inhibiting neuronal differentiation. Dev. Biol. 244, 329-341. doi: 10.1006/dbio.2002.0598

Arvidsson, A., Collin, T., Kirik, D., Kokaia, Z., and Lindvall, O. (2002). Neuronal replacement from endogenous precursors in the adult brain after stroke. Nat. Med. 8, 963-970. doi: 10.1038/nm747

Asher, R. A., Morgenstern, D. A., Fidler, P. S., Adcock, K. H., Oohira, A., Braistead, J. E., et al. (2000). Neurocan is upregulated in injured brain and in cytokinetreated astrocytes. J. Neurosci. 20, 2427-2438.

Asher, R. A., Morgenstern, D. A., Shearer, M. C., Adcock, K. H., Pesheva, P., and Fawcett, J. W. (2002). Versican is upregulated in CNS injury and is a product of oligodendrocyte lineage cells. J. Neurosci. 22, 2225-2236.

Bacigaluppi, M., Pluchino, S., Peruzzotti-Jametti, L., Kilic, E., Kilic, U., Salani, G., et al. (2009). Delayed post-ischaemic neuroprotection following systemic neural stem cell transplantation involves multiple mechanisms. Brain 132, 2239-2251. doi: 10.1093/brain/awp174

Baeten, K. M., and Akassoglou, K. (2011). Extracellular matrix and matrix receptors in blood-brain barrier formation and stroke. Dev. Neurobiol. 71, 1018-1039. doi: 10.1002/dneu.20954

Barker, R. A., Dunnett, S. B., Faissner, A., and Fawcett, J. W. (1996). The time course of loss of dopaminergic neurons and the gliotic reaction surrounding grafts of embryonic mesencephalon to the striatum. Exp. Neurol. 141, 79-93. doi: 10. 1006/exnr.1996.0141

Barkho, B. Z., Munoz, A. E., Li, X., Li, L., Cunningham, L. A., and Zhao, X. (2008). Endogenous matrix metalloproteinase (MMP)-3 and MMP-9 promote the differentiation and migration of adult neural progenitor cells in response to chemokines. Stem Cells 26, 3139-3149. doi: 10.1634/stemcells.20080519 
Barnabé-Heider, F., Göritz, C., Sabelström, H., Takebayashi, H., Pfrieger, F. W., Meletis, K., et al. (2010). Origin of new glial cells in intact and injured adult spinal cord. Cell Stem Cell 7, 470-482. doi: 10.1016/j.stem.2010.07.014

Barnea, G., Grumet, M., Milev, P., Silvennoinen, O., Levy, J. B., Sap, J., et al. (1994). Receptor tyrosine phosphatase beta is expressed in the form of proteoglycan and binds to the extracellular matrix protein tenascin. J. Biol. Chem. 269, 1434914352.

Becker, T., Anliker, B., Becker, C. G., Taylor, J., Schachner, M., Meyer, R. L., et al. (2000). Tenascin-R inhibits regrowth of optic fibers in vitro and persists in the optic nerve of mice after injury. Glia 29, 330-346. doi: 10.1002/(sici)10981136(20000215)29:4<330::aid-glia4>3.0.c0;2-1

Beggah, A. T., Dours-Zimmermann, M. T., Barras, F. M., Brosius, A., Zimmermann, D. R., and Zurn, A. D. (2005). Lesion-induced differential expression and cell association of Neurocan, Brevican, Versican V1 and V2 in the mouse dorsal root entry zone. Neuroscience 133, 749-762. doi: 10.1016/j.neuroscience.2005. 03.005

Belkin, A. M., and Stepp, M. A. (2000). Integrins as receptors for laminins. Microsc. Res. Tech. 51, 280-301. doi: 10.1002/1097-0029(20001101)51:3<280::aidjemt7 > 3.0.co;2-o

Benner, E. J., Luciano, D., Jo, R., Abdi, K., Paez-Gonzalez, P., Sheng, H., et al. (2013). Protective astrogenesis from the SVZ niche after injury is controlled by notch modulator Thbs4. Nature 497, 369-373. doi: 10.1038/nature12069

Besser, M., Horvat-Bröcker, A., Eysel, U. T., and Faissner, A. (2009). Differential expression of receptor protein tyrosine phosphatases accompanies the reorganisation of the retina upon laser lesion. Exp. Brain Res. 198, 37-47. doi: 10. 1007/s00221-009-1932-0

Biber, K., Neumann, H., Inoue, K., and Boddeke, H. W. (2007). Neuronal 'On' and 'Off' signals control microglia. Trends Neurosci. 30, 596-602. doi: 10.1016/j.tins. 2007.08.007

Bignami, A., Raju, T., and Dahl, D. (1982). Localization of vimentin, the nonspecific intermediate filament protein, in embryonal glia and in early differentiating neurons. In vivo and in vitro immunofluorescence study of the rat embryo with vimentin and neurofilament antisera. Dev. Biol. 91, 286-295. doi: 10.1016/00121606(82)90035-5

Bradbury, E. J., Moon, L. D., Popat, R. J., King, V. R., Bennett, G. S., Patel, P. N., et al. (2002). Chondroitinase $\mathrm{ABC}$ promotes functional recovery after spinal cord injury. Nature 416, 636-640. doi: 10.1038/416636a

Brenner, M. (2014). Role of GFAP in CNS injuries. Neurosci. Lett. 565, 7-13. doi: 10. 1016/j.neulet.2014.01.055

Brizzi, M. F., Tarone, G., and Defilippi, P. (2012). Extracellular matrix, integrins and growth factors as tailors of the stem cell niche. Curr. Opin. Cell Biol. 24, 645-651. doi: 10.1016/j.ceb.2012.07.001

Brosius Lutz, A., and Barres, B. A. (2014). Contrasting the glial response to axon injury in the central and peripheral nervous systems. Dev. Cell 28, 7-17. doi: 10. 1016/j.devcel.2013.12.002

Brown, J. M., Xia, J., Zhuang, B., Cho, K. S., Rogers, C. J., Gama, C. I., et al. (2012). A sulfated carbohydrate epitope inhibits axon regeneration after injury. Proc. Natl. Acad. Sci. U S A 109, 4768-4773. doi: 10.1073/pnas.1121318109

Buddensiek, J., Dressel, A., Kowalski, M., Storch, A., and Sabolek, M. (2009). Adult cerebrospinal fluid inhibits neurogenesis but facilitates gliogenesis from fetal rat neural stem cells. J. Neurosci. Res. 87, 3054-3066. doi: 10.1002/jnr. 22150

Budinich, C. S., Chen, H., Lowe, D., Rosenberger, J. G., Bernstock, J. D., and McCabe, J. T. (2012). Mouse brain PSA-NCAM levels are altered by graded-controlled cortical impact injury. Neural Plast. 2012:378307. doi: 10. $1155 / 2012 / 378307$

Buffo, A., Rite, I., Tripathi, P., Lepier, A., Colak, D., Horn, A. P., et al. (2008). Origin and progeny of reactive gliosis: a source of multipotent cells in the injured brain. Proc. Natl. Acad. Sci. U S A 105, 3581-3586. doi: 10.1073/pnas.0709002105

Buffo, A., Rolando, C., and Ceruti, S. (2010). Astrocytes in the damaged brain: molecular and cellular insights into their reactive response and healing potential. Biochem. Pharmacol. 79, 77-89. doi: 10.1016/j.bcp.2009.09.014

Bundesen, L. Q., Scheel, T. A., Bregman, B. S., and Kromer, L. F. (2003). Ephrin-B2 and EphB2 regulation of astrocyte-meningeal fibroblast interactions in response to spinal cord lesions in adult rats. J. Neurosci. 23, 7789-7800.

Burda, J. E., and Sofroniew, M. V. (2014). Reactive gliosis and the multicellular response to CNS damage and disease. Neuron 81, 229-248. doi: 10.1016/j. neuron.2013.12.034
Burnside, E. R., and Bradbury, E. J. (2014). Manipulating the extracellular matrix and its role in brain and spinal cord plasticity and repair. Neuropathol. Appl. Neurobiol. 40, 26-59. doi: 10.1111/nan.12114

Calof, A. L., Campanero, M. R., O’Rear, J. J., Yurchenco, P. D., and Lander, A. D. (1994). Domain-specific activation of neuronal migration and neurite outgrowth-promoting activities of laminin. Neuron 13, 117-130. doi: 10 . 1016/0896-6273(94)90463-4

Campos, L. S. (2005). Betal integrins and neural stem cells: making sense of the extracellular environment. Bioessays 27, 698-707. doi: 10.1002/bies.20256

Candelario-Jalil, E., Yang, Y., and Rosenberg, G. A. (2009). Diverse roles of matrix metalloproteinases and tissue inhibitors of metalloproteinases in neuroinflammation and cerebral ischemia. Neuroscience 158, 983-994. doi: 10. 1016/j.neuroscience.2008.06.025

Carbonell, W. S., Murase, S., Horwitz, A. F., and Mandell, J. W. (2005). Migration of perilesional microglia after focal brain injury and modulation by CC chemokine receptor 5: an in situ time-lapse confocal imaging study. J. Neurosci. 25, 70407047. doi: 10.1523/jneurosci.5171-04.2005

Carmeliet, P. (2003). Blood vessels and nerves: common signals, pathways and diseases. Nat. Rev. Genet. 4, 710-720. doi: 10.1038/nrg1158

Carulli, D., Laabs, T., Geller, H. M., and Fawcett, J. W. (2005). Chondroitin sulfate proteoglycans in neural development and regeneration. Curr. Opin. Neurobiol. 15, 116-120. doi: 10.1016/j.conb.2005.03.018

Castellani, V., Chédotal, A., Schachner, M., Faivre-Sarrailh, C., and Rougon, G. (2000). Analysis of the L1-deficient mouse phenotype reveals cross-talk between Sema3A and L1 signaling pathways in axonal guidance. Neuron 27, 237-249. doi: 10.1016/s0896-6273(00)00033-7

Chen, M. S., Huber, A. B., van der Haar, M. E., Frank, M., Schnell, L., and Spillmann, A. A. (2000). Nogo-A is a myelin-associated neurite outgrowth inhibitor and an antigen for monoclonal antibody IN-1. Nature 403, 434-439. doi: $10.1038 / 35000219$

Chen, J., Joon Lee, H., Jakovcevski, I., Shah, R., Bhagat, N., Loers, G., et al. (2010). The extracellular matrix glycoprotein tenascin-C is beneficial for spinal cord regeneration. Mol. Ther. 18, 1769-1777. doi: 10.1038/mt.2010.133

Chen, X. R., Liao, S. J., Ye, L. X., Gong, Q., Ding, Q., Zeng, J. S., et al. (2014). Neuroprotective effect of chondroitinase ABC on primary and secondary brain injury after stroke in hypertensive rats. Brain Res. 1543, 324-333. doi: 10.1016/j. brainres.2013.12.002

Chiquet-Ehrismann, R., and Chiquet, M. (2003). Tenascins: regulation and putative functions during pathological stress. J. Pathol. 200, 488-499. doi: 10.1002/path. 1415

Chiquet-Ehrismann, R., Orend, G., Chiquet, M., Tucker, R. P., and Midwood, K. S. (2014). Tenascins in stem cell niches. Matrix Biol. doi: 10.1016/j.matbio.2014. 01.007. [Epub ahead of print].

Chopp, M., Li, Y., and Zhang, Z. G. (2009). Mechanisms underlying improved recovery of neurological function after stroke in the rodent after treatment with neurorestorative cell-based therapies. Stroke 40, S143-S145. doi: 10. 1161/strokeaha.108.533141

Chow, J. P., Fujikawa, A., Shimizu, H., Suzuki, R., and Noda, M. (2008). Metalloproteinase- and gamma-secretase-mediated cleavage of protein-tyrosine phosphatase receptor type Z. J. Biol. Chem. 283, 30879-30889. doi: 10.1074/jbc. m802976200

Christopherson, K. S., Ullian, E. M., Stokes, C. C., Mullowney, C. E., Hell, J. W., Agah, A., et al. (2005). Thrombospondins are astrocyte-secreted proteins that promote CNS synaptogenesis. Cell 120, 421-433. doi: 10.1016/j.cell.2004. 12.020

Clark, R. A. (2008). Synergistic signaling from extracellular matrix-growth factor complexes. J. Invest. Dermatol. 128, 1354-1355. doi: 10.1038/jid.2008.75

Coles, C. H., Shen, Y., Tenney, A. P., Siebold, C., Sutton, G. C., Lu, W., et al. (2011). Proteoglycan-specific molecular switch for RPTPsigma clustering and neuronal extension. Science 332, 484-488. doi: 10.1126/science. 1200840

Condic, M. L., and Lemons, M. L. (2002). Extracellular matrix in spinal cord regeneration: getting beyond attraction and inhibition. Neuroreport 13, A37A48. doi: 10.1097/00001756-200203040-00002

Craveiro, L. M., Weinmann, O., Roschitzki, B., Gonzenbach, R. R., Zörner, B., Montani, L., et al. (2013). Infusion of anti-Nogo-A antibodies in adult rats increases growth and synapse related proteins in the absence of behavioral alterations. Exp. Neurol. 250, 52-68. doi: 10.1016/j.expneurol.2013. 09.015 
Cregg, J. M., DePaul, M. A., Filous, A. R., Lang, B. T., Tran, A., and Silver, J. (2014). Functional regeneration beyond the glial scar. Exp. Neurol. 253, $197-$ 207. doi: 10.1016/j.expneurol.2013.12.024

Cui, Y. F., Xu, J. C., Hargus, G., Jakovcevski, I., Schachner, M., and Bernreuther, C. (2011). Embryonic stem cell-derived L1 overexpressing neural aggregates enhance recovery after spinal cord injury in mice. PLoS One 6:e17126. doi: 10. 1371/journal.pone.0017126

Czopka, T., von Holst, A., ffrench-Constant, C., and Faissner, A. (2010). Regulatory mechanisms that mediate tenascin C-dependent inhibition of oligodendrocyte precursor differentiation. J. Neurosci. 30, 12310-12322. doi: 10.1523/jneurosci. 4957-09.2010

Daar, I. O. (2012). Non-SH2/PDZ reverse signaling by ephrins. Semin. Cell Dev. Biol. 23, 65-74. doi: 10.1016/j.semcdb.2011.10.012

Das, M., Mohapatra, S., and Mohapatra, S. S. (2012). New perspectives on central and peripheral immune responses to acute traumatic brain injury. J. Neuroinflammation 9:236. doi: 10.1186/1742-2094-9-236

Davies, J. E., Tang, X., Denning, J. W., Archibald, S. J., and Davies, S. J. (2004). Decorin suppresses neurocan, brevican, phosphacan and NG2 expression and promotes axon growth across adult rat spinal cord injuries. Eur. J. Neurosci. 19, 1226-1242. doi: 10.1111/j.1460-9568.2004.03184.x

Deckner, M., Lindholm, T., Cullheim, S., and Risling, M. (2000). Differential expression of tenascin-C, tenascin- $\mathrm{R}$, tenascin/J1 and tenascin- $\mathrm{X}$ in spinal cord scar tissue and in the olfactory system. Exp. Neurol. 166, 350-362. doi: 10. 1006/exnr.2000.7543

Deepa, S. S., Umehara, Y., Higashiyama, S., Itoh, N., and Sugahara, K. (2002). Specific molecular interactions of oversulfated chondroitin sulfate $\mathrm{E}$ with various heparin-binding growth factors. Implications as a physiological binding partner in the brain and other tissues. J. Biol. Chem. 277, 43707-43716. doi: 10.1074/jbc. m207105200

De Simone, R., Ambrosini, E., Carnevale, D., Ajmone-Cat, M. A., and Minghetti, L. (2007). NGF promotes microglial migration through the activation of its high affinity receptor: modulation by TGF-beta. J. Neuroimmunol. 190, 53-60. doi: 10.1016/j.jneuroim.2007.07.020

Dimitrijevic, O. B., Stamatovic, S. M., Keep, R. F., and Andjelkovic, A. V. (2006). Effects of the chemokine CCL2 on blood-brain barrier permeability during ischemia-reperfusion injury. J. Cereb. Blood Flow Metab. 26, 797-810. doi: 10. 1038/sj.jcbfm.9600229

Ding, X., Li, Y., Liu, Z., Zhang, J., Cui, Y., Chen, X., et al. (2013). The sonic hedgehog pathway mediates brain plasticity and subsequent functional recovery after bone marrow stromal cell treatment of stroke in mice. J. Cereb. Blood Flow Metab. 33, 1015-1024. doi: 10.1038/jcbfm.2013.50

Dityatev, A., and Schachner, M. (2003). Extracellular matrix molecules and synaptic plasticity. Nat. Rev. Neurosci. 4, 456-468. doi: 10.1038/nrn1115

Dobbertin, A., Czvitkovich, S., Theocharidis, U., Garwood, J., Andrews, M. R., Properzi, F., et al. (2010). Analysis of combinatorial variability reveals selective accumulation of the fibronectin type III domains B and D of tenascinC in injured brain. Exp. Neurol. 225, 60-73. doi: 10.1016/j.expneurol.2010. 04.019

Dobbertin, A., Rhodes, K. E., Garwood, J., Properzi, F., Heck, N., Rogers, J. H., et al. (2003). Regulation of RPTPbeta/phosphacan expression and glycosaminoglycan epitopes in injured brain and cytokine-treated glia. Mol. Cell. Neurosci. 24, 951971. doi: 10.1016/s1044-7431(03)00257-4

Doetsch, F., Caillé, I., Lim, D. A., García-Verdugo, J. M., and AlvarezBuylla, A. (1999). Subventricular zone astrocytes are neural stem cells in the adult mammalian brain. Cell 97, 703-716. doi: 10.1016/s0092-8674(00) 80783-7

Doetsch, F., García-Verdugo, J. M., and Alvarez-Buylla, A. (1997). Cellular composition and three-dimensional organization of the subventricular germinal zone in the adult mammalian brain. J. Neurosci. 17, 5046-5061.

Domogatskaya, A., Rodin, S., and Tryggvason, K. (2012). Functional diversity of laminins. Annu. Rev. Cell Dev. Biol. 28, 523-553. doi: 10.1146/annurev-cellbio101011-155750

Donnelly, D. J., and Popovich, P. G. (2008). Inflammation and its role in neuroprotection, axonal regeneration and functional recovery after spinal cord injury. Exp. Neurol. 209, 378-388. doi: 10.1016/j.expneurol.2007. 06.009

Dou, C. L., and Levine, J. M. (1994). Inhibition of neurite growth by the NG2 chondroitin sulfate proteoglycan. J. Neurosci. 14, 7616-7628.
Dugas, J. C., Mandemakers, W., Rogers, M., Ibrahim, A., Daneman, R., and Barres, B. A. (2008). A novel purification method for CNS projection neurons leads to the identification of brain vascular cells as a source of trophic support for corticospinal motor neurons. J. Neurosci. 28, 8294-8305. doi: 10.1523/JNEUROSCI. 2010-08.2008

Eddleston, M., and Mucke, L. (1993). Molecular profile of reactive astrocytesimplications for their role in neurologic disease. Neuroscience 54, 15-36. doi: 10. 1016/0306-4522(93)90380-x

Elkabes, S., DiCicco-Bloom, E. M., and Black, I. B. (1996). Brain microglia/macrophages express neurotrophins that selectively regulate microglial proliferation and function. J. Neurosci. 16, 2508-2521.

Ellison, J. A., Barone, F. C., and Feuerstein, G. Z. (1999). Matrix remodeling after stroke. De novo expression of matrix proteins and integrin receptors. Ann. NY Acad. Sci. 890, 204-222. doi: 10.1111/j.1749-6632.1999.tb07996.x

Emery, D. L., Royo, N. C., Fischer, I., Saatman, K. E., and McIntosh, T. K. (2003). Plasticity following injury to the adult central nervous system: is recapitulation of a developmental state worth promoting? J. Neurotrauma 20, 1271-1292. doi: $10.1089 / 089771503322686085$

Faissner, A. (1997). The tenascin gene family in axon growth and guidance. Cell Tissue Res. 290, 331-341. doi: 10.1007/978-3-642-60905-3_19

Faissner, A., Clement, A., Lochter, A., Streit, A., Mandl, C., and Schachner, M. (1994). Isolation of a neural chondroitin sulfate proteoglycan with neurite outgrowth promoting properties. J. Cell Biol. 126, 783-799. doi: 10.1083/jcb. 126.3.783

Faissner, A., Pyka, M., Geissler, M., Sobik, T., Frischknecht, R., Gundelfinger, E. D., et al. (2010). Contributions of astrocytes to synapse formation and maturation-Potential functions of the perisynaptic extracellular matrix. Brain Res. Rev. 63, 26-38. doi: 10.1016/j.brainresrev.2010.01.001

Falo, M. C., Reeves, T. M., and Phillips, L. L. (2008). Agrin expression during synaptogenesis induced by traumatic brain injury. J. Neurotrauma 25, 769-783. doi: 10.1089/neu.2008.0511

Filla, M. S., Dam, P., and Rapraeger, A. C. (1998). The cell surface proteoglycan syndecan-1 mediates fibroblast growth factor-2 binding and activity. J. Cell. Physiol. 174, 310-321. doi: 10.1002/(sici)1097-4652(199803)174:3<310::aidjcp5 $>3.0 . \operatorname{co} ; 2-\mathrm{r}$

Filmus, J., and Capurro, M. (2014). The role of glypicans in hedgehog signaling. Matrix Biol. 35, 248-252. doi: 10.1016/j.matbio.2013.12.007

Fournier, A. E., Takizawa, B. T., and Strittmatter, S. M. (2003). Rho kinase inhibition enhances axonal regeneration in the injured CNS. J. Neurosci. 23, 1416-1423.

Fraichard, A., Chassande, O., Bilbaut, G., Dehay, C., Savatier, P., and Samarut, J. (1995). In vitro differentiation of embryonic stem cells into glial cells and functional neurons. J. Cell Sci. 108(Pt. 10), 3181-3188.

Friedlander, D. R., Milev, P., Karthikeyan, L., Margolis, R. K., Margolis, R. U., and Grumet, M. (1994). The neuronal chondroitin sulfate proteoglycan neurocan binds to the neural cell adhesion molecules Ng-CAM/L1/NILE and N-CAM and inhibits neuronal adhesion and neurite outgrowth. J. Cell Biol. 125, 669-680. doi: $10.1083 /$ jcb.125.3.669

Fuccillo, M., Joyner, A. L., and Fishell, G. (2006). Morphogen to mitogen: the multiple roles of hedgehog signalling in vertebrate neural development. Nat. Rev. Neurosci. 7, 772-783. doi: 10.1038/nrn1990

Fuller, M. L., DeChant, A. K., Rothstein, B., Caprariello, A., Wang, R., Hall, A. K., et al. (2007). Bone morphogenetic proteins promote gliosis in demyelinating spinal cord lesions. Ann. Neurol. 62, 288-300. doi: 10.1002/ana. 21179

Garcion, E., Halilagic, A., Faissner, A., and ffrench-Constant, C. (2004). Generation of an environmental niche for neural stem cell development by the extracellular matrix molecule tenascin C. Development 131, 3423-3432. doi: 10.1242/dev. 01202

Garwood, J., Heck, N., Reichardt, F., and Faissner, A. (2003). Phosphacan short isoform, a novel non-proteoglycan variant of phosphacan/receptor protein tyrosine phosphatase-beta, interacts with neuronal receptors and promotes neurite outgrowth. J. Biol. Chem. 278, 24164-24173. doi: 10.1074/jbc. m211721200

Gates, M. A., Thomas, L. B., Howard, E. M., Laywell, E. D., Sajin, B., Faissner, A., et al. (1995). Cell and molecular analysis of the developing and adult mouse subventricular zone of the cerebral hemispheres. J. Comp. Neurol. 361, 249-266. doi: $10.1002 /$ cne. 903610205 
Gattazzo, F., Urciuolo, A., and Bonaldo, P. (2014). Extracellular matrix: a dynamic microenvironment for stem cell niche. Biochim. Biophys. Acta 1840, 2506-2519. doi: 10.1016/j.bbagen.2014.01.010

Geissler, M., Gottschling, C., Aguado, A., Rauch, U., Wetzel, C. H., Hatt, H., et al. (2013). Primary hippocampal neurons, which lack four crucial extracellular matrix molecules, display abnormalities of synaptic structure and function and severe deficits in perineuronal net formation. J. Neurosci. 33, 7742-7755. doi: 10. 1523/jneurosci.3275-12.2013

Givogri, M. I., de Planell, M., Galbiati, F., Superchi, D., Gritti, A., Vescovi, A., et al. (2006). Notch signaling in astrocytes and neuroblasts of the adult subventricular zone in health and after cortical injury. Dev. Neurosci. 28, 81-91. doi: 10 $1159 / 000090755$

Gladson, C. L. (1999). The extracellular matrix of gliomas: modulation of cell function. J. Neuropathol. Exp. Neurol. 58, 1029-1040. doi: 10.1097/00005072199910000-00001

Goldshmit, Y., Galea, M. P., Wise, G., Bartlett, P. F., and Turnley, A. M. (2004). Axonal regeneration and lack of astrocytic gliosis in EphA4-deficient mice. J. Neurosci. 24, 10064-10073. doi: 10.1523/JNEUROSCI.2981-04.2004

Goldshmit, Y., McLenachan, S., and Turnley, A. (2006). Roles of Eph receptors and ephrins in the normal and damaged adult CNS. Brain Res. Rev. 52, 327-345. doi: 10.1016/j.brainresrev.2006.04.006

Gordon, P. B., Choi, H. U., Conn, G., Ahmed, A., Ehrmann, B., Rosenberg, L., et al. (1989). Extracellular matrix heparan sulfate proteoglycans modulate the mitogenic capacity of acidic fibroblast growth factor. J. Cell. Physiol. 140, 584592. doi: $10.1002 /$ jcp. 1041400325

Göritz, C., Dias, D. O., Tomilin, N., Barbacid, M., Shupliakov, O., and Frisén, J. (2011). A pericyte origin of spinal cord scar tissue. Science 333, 238-242. doi: 10. 1126/science. 1203165

Gottschall, P. E., and Yu, X. (1995). Cytokines regulate gelatinase A and B (matrix metalloproteinase 2 and 9) activity in cultured rat astrocytes. J. Neurochem. 64, 1513-1520. doi: 10.1046/j.1471-4159.1995.64041513.x

Gris, P., Tighe, A., Levin, D., Sharma, R., and Brown, A. (2007). Transcriptional regulation of scar gene expression in primary astrocytes. Glia 55, 1145-1155. doi: 10.1002/glia.20537

Guan, J. L. (1997). Focal adhesion kinase in integrin signaling. Matrix Biol. 16, 195 200. doi: 10.1016/S0945-053X(97)90008-1

Guo, W., and Giancotti, F. G. (2004). Integrin signalling during tumour progression. Nat. Rev. Mol. Cell Biol. 5, 816-826. doi: 10.1038/nrm1490

Guo, Z., Zhang, L., Wu, Z., Chen, Y., Wang, F., and Chen, G. (2014). In vivo direct reprogramming of reactive glial cells into functional neurons after brain injury and in an Alzheimer's disease model. Cell Stem Cell 14, 188-202. doi: 10.1016/j. stem.2013.12.001

Haas, C. A., Rauch, U., Thon, N., Merten, T., and Deller, T. (1999). Entorhinal cortex lesion in adult rats induces the expression of the neuronal chondroitin sulfate proteoglycan neurocan in reactive astrocytes. J. Neurosci. 19, 9953-9963.

Hagino, S., Iseki, K., Mori, T., Zhang, Y., Hikake, T., Yokoya, S., et al. (2003). Slit and glypican-1 mRNAs are coexpressed in the reactive astrocytes of the injured adult brain. Glia 42, 130-138. doi: 10.1002/glia.10207

Hampton, D. W., Asher, R. A., Kondo, T., Steeves, J. D., Ramer, M. S., and Fawcett, J. W. (2007). A potential role for bone morphogenetic protein signalling in glial cell fate determination following adult central nervous system injury in vivo. Eur. J. Neurosci. 26, 3024-3035. doi: 10.1111/j.1460-9568.2007.05940.x

Han, S. S., Liu, Y., Tyler-Polsz, C., Rao, M. S., and Fischer, I. (2004). Transplantation of glial-restricted precursor cells into the adult spinal cord: survival, glialspecific differentiation and preferential migration in white matter. Glia 45, 1-16. doi: $10.1002 /$ glia.10282

Han, D. W., Tapia, N., Hermann, A., Hemmer, K., Höing, S., Araúzo-Bravo, M. J., et al. (2012). Direct reprogramming of fibroblasts into neural stem cells by defined factors. Cell Stem Cell 10, 465-472. doi: 10.1016/j.stem.2012.02.021

Harroch, S., Furtado, G. C., Brueck, W., Rosenbluth, J., Lafaille, J., Chao, M., et al. (2002). A critical role for the protein tyrosine phosphatase receptor type $\mathrm{Z}$ in functional recovery from demyelinating lesions. Nat. Genet. 32, 411-414. doi: $10.1038 /$ ng1004

Hausmann, R., and Betz, P. (2001). Course of glial immunoreactivity for vimentin, tenascin and alphal-antichymotrypsin after traumatic injury to human brain. Int. J. Legal Med. 114, 338-342. doi: 10.1007/s004140000199

Haylock-Jacobs, S., Keough, M. B., Lau, L., and Yong, V. W. (2011). Chondroitin sulphate proteoglycans: extracellular matrix proteins that regulate immunity of the central nervous system. Autoimmun. Rev. 10, 766-772. doi: 10.1016/j.autrev. 2011.05.019

Heck, N., Garwood, J., Dobbertin, A., Calco, V., Sirko, S., Mittmann, T., et al. (2007). Evidence for distinct leptomeningeal cell-dependent paracrine and EGFlinked autocrine regulatory pathways for suppression of fibrillar collagens in astrocytes. Mol. Cell. Neurosci. 36, 71-85. doi: 10.1016/j.mcn.2007.06.002

Hetman, M., and Xia, Z. (2000). Signaling pathways mediating anti-apoptotic action of neurotrophins. Acta Neurobiol. Exp. (Wars) 60, 531-545.

Hill, W. D., Hess, D. C., Martin-Studdard, A., Carothers, J. J., Zheng, J., Hale, D., et al. (2004). SDF-1 (CXCL12) is upregulated in the ischemic penumbra following stroke: association with bone marrow cell homing to injury. J. Neuropathol. Exp. Neurol. 63, 84-96.

Hirano, S., Yonezawa, T., Hasegawa, H., Hattori, S., Greenhill, N. S., Davis, P. F., et al. (2004). Astrocytes express type VIII collagen during the repair process of brain cold injury. Biochem. Biophys. Res. Commun. 317, 437-443. doi: 10.1016/j. bbrc.2004.03.049

Hsu, J. Y., Bourguignon, L. Y., Adams, C. M., Peyrollier, K., Zhang, H., Fandel, T., et al. (2008). Matrix metalloproteinase-9 facilitates glial scar formation in the injured spinal cord. J. Neurosci. 28, 13467-13477. doi: 10.1523/jneurosci.228708.2008

Ida, M., Shuo, T., Hirano, K., Tokita, Y., Nakanishi, K., Matsui, F., et al. (2006). Identification and functions of chondroitin sulfate in the milieu of neural stem cells. J. Biol. Chem. 281, 5982-5991. doi: 10.1074/jbc.m507130200

Ikegami, T., Nakamura, M., Yamane, J., Katoh, H., Okada, S., Iwanami, A., et al. (2005). Chondroitinase ABC combined with neural stem/progenitor cell transplantation enhances graft cell migration and outgrowth of growthassociated protein-43-positive fibers after rat spinal cord injury. Eur. J. Neurosci. 22, 3036-3046. doi: 10.1111/j.1460-9568.2005.04492.x

Imitola, J., Raddassi, K., Park, K. I., Mueller, F. J., Nieto, M., Teng, Y. D., et al. (2004). Directed migration of neural stem cells to sites of CNS injury by the stromal cellderived factor lalpha/CXC chemokine receptor 4 pathway. Proc. Natl. Acad. Sci. U S A 101, 18117-18122. doi: 10.1073/pnas.0408258102

Iseki, K., Hagino, S., Mori, T., Zhang, Y., Yokoya, S., Takaki, H., et al. (2002). Increased syndecan expression by pleiotrophin and FGF receptor-expressing astrocytes in injured brain tissue. Glia 39, 1-9. doi: 10.1002/glia.10078

Ishibashi, S., Kuroiwa, T., Sakaguchi, M., Sun, L., Kadoya, T., Okano, H., et al. (2007). Galectin-1 regulates neurogenesis in the subventricular zone and promotes functional recovery after stroke. Exp. Neurol. 207, 302-313. doi: 10.1016/j. expneurol.2007.06.024

Ishii, K., Nakamura, M., Dai, H., Finn, T. P., Okano, H., Toyama, Y., et al. (2006) Neutralization of ciliary neurotrophic factor reduces astrocyte production from transplanted neural stem cells and promotes regeneration of corticospinal tract fibers in spinal cord injury. J. Neurosci. Res. 84, 1669-1681. doi: 10.1002/jnr. 21079

Jakeman, L. B., Chen, Y., Lucin, K. M., and McTigue, D. M. (2006). Mice lacking L1 cell adhesion molecule have deficits in locomotion and exhibit enhanced corticospinal tract sprouting following mild contusion injury to the spinal cord. Eur. J. Neurosci. 23, 1997-2011. doi: 10.1111/j.1460-9568.2006.04721.x

Jakovcevski, I., Miljkovic, D., Schachner, M., and Andjus, P. R. (2013). Tenascins and inflammation in disorders of the nervous system. Amino Acids 44, 1115 1127. doi: 10.1007/s00726-012-1446-0

Jin, K., Zhu, Y., Sun, Y., Mao, X. O., Xie, L., and Greenberg, D. A. (2002). Vascular endothelial growth factor (VEGF) stimulates neurogenesis in vitro and in vivo. Proc. Natl. Acad. Sci. U S A 99, 11946-11950. doi: 10.1073/pnas.182296499

Joester, A., and Faissner, A. (1999). Evidence for combinatorial variability of tenascin-C isoforms and developmental regulation in the mouse central nervous system. J. Biol. Chem. 274, 17144-17151. doi: 10.1074/jbc.274.24.17144

Joester, A., and Faissner, A. (2001). The structure and function of tenascins in the nervous system. Matrix Biol. 20, 13-22. doi: 10.1016/s0945-053x(00)00136-0

Jones, F. S., and Jones, P. L. (2000a). The tenascin family of ECM glycoproteins: structure, function and regulation during embryonic development and tissue remodeling. Dev. Dyn. 218, 235-259. doi: 10.1002/(sici)10970177(200006)218:2<235::aid-dvdy2>3.0.co;2-g

Jones, P. L., and Jones, F. S. (2000b). Tenascin-C in development and disease: gene regulation and cell function. Matrix Biol. 19, 581-596. doi: 10.1016/s0945053x(00)00106-2

Jones, L. L., Margolis, R. U., and Tuszynski, M. H. (2003). The chondroitin sulfate proteoglycans neurocan, brevican, phosphacan and versican are differentially 
regulated following spinal cord injury. Exp. Neurol. 182, 399-411. doi: 10. 1016/S0014-4886(03)00087-6

Jones, L. L., Yamaguchi, Y., Stallcup, W. B., and Tuszynski, M. H. (2002). NG2 is a major chondroitin sulfate proteoglycan produced after spinal cord injury and is expressed by macrophages and oligodendrocyte progenitors. J. Neurosci. 22, 2792-2803.

Jung, G., Sun, J., Petrowitz, B., Riecken, K., Kruszewski, K., Jankowiak, W., et al. (2013). Genetically modified neural stem cells for a local and sustained delivery of neuroprotective factors to the dystrophic mouse retina. Stem Cells Transl. Med. 2, 1001-1010. doi: 10.5966/sctm.2013-0013

Kamei, N., Kwon, S. M., Ishikawa, M., Ii, M., Nakanishi, K., Yamada, K., et al. (2012). Endothelial progenitor cells promote astrogliosis following spinal cord injury through Jagged1-dependent notch signaling. J. Neurotrauma 29, 17581769. doi: 10.1089/neu.2011.2139

Kamphuis, W., Mamber, C., Moeton, M., Kooijman, L., Sluijs, J. A., Jansen, A. H., et al. (2012). GFAP isoforms in adult mouse brain with a focus on neurogenic astrocytes and reactive astrogliosis in mouse models of Alzheimer disease. PLoS One 7:e42823. doi: 10.1371/journal.pone.0042823

Karetko-Sysa, M., Skangiel-Kramska, J., and Nowicka, D. (2011). Disturbance of perineuronal nets in the perilesional area after photothrombosis is not associated with neuronal death. Exp. Neurol. 231, 113-126. doi: 10.1016/j.expneurol. 2011.05 .022

Karlén, A., Karlsson, T. E., Mattsson, A., Lundströmer, K., Codeluppi, S., Pham, T. M., et al. (2009). Nogo receptor 1 regulates formation of lasting memories. Proc. Natl. Acad. Sci. U S A 106, 20476-20481. doi: 10.1073/pnas.09053 90106

Karus, M., Denecke, B., ffrench-Constant, C., Wiese, S., and Faissner, A. (2011). The extracellular matrix molecule tenascin $\mathrm{C}$ modulates expression levels and territories of key patterning genes during spinal cord astrocyte specification. Development 138, 5321-5331. doi: 10.1242/dev.067413

Kazanis, I., and ffrench-Constant, C. (2011). Extracellular matrix and the neural stem cell niche. Dev. Neurobiol. 71, 1006-1017. doi: 10.1002/dneu.20970

Kettenmann, H., Hanisch, U. K., Noda, M., and Verkhratsky, A. (2011). Physiology of microglia. Physiol. Rev. 91, 461-553. doi: 10.1152/physrev.00011.2010

Kim, H., Ahn, M., Choi, S., Kim, M., Sim, K. B., Kim, J., et al. (2013). Potential role of fibronectin in microglia/macrophage activation following cryoinjury in the rat brain: an immunohistochemical study. Brain Res. 1502, 11-19. doi: 10. 1016/j.brainres.2013.01.043

Kim, J. B., Zaehres, H., Wu, G., Gentile, L., Ko, K., Sebastiano, V., et al. (2008). Pluripotent stem cells induced from adult neural stem cells by reprogramming with two factors. Nature 454, 646-650. doi: 10.1038/nature07061

Kinouchi, R., Takeda, M., Yang, L., Wilhelmsson, U., Lundkvist, A., Pekny, M., et al. (2003). Robust neural integration from retinal transplants in mice deficient in GFAP and vimentin. Nat. Neurosci. 6, 863-868. doi: 10.1038/nn1088

Klausmeyer, A., Garwood, J., and Faissner, A. (2007). Differential expression of phosphacan/RPTPbeta isoforms in the developing mouse visual system. J. Comp. Neurol. 504, 659-679. doi: 10.1002/cne.21479

Kokaia, Z., Martino, G., Schwartz, M., and Lindvall, O. (2012). Cross-talk between neural stem cells and immune cells: the key to better brain repair? Nat. Neurosci. 15, 1078-1087. doi: 10.1038/nn.3163

Kokovay, E., Goderie, S., Wang, Y., Lotz, S., Lin, G., Sun, Y., et al. (2010). Adult SVZ lineage cells home to and leave the vascular niche via differential responses to SDF1/CXCR4 signaling. Cell Stem Cell 7, 163-173. doi: 10.1016/j.stem.2010. 05.019

Komitova, M., Serwanski, D. R., Lu, Q. R., and Nishiyama, A. (2011). NG2 cells are not a major source of reactive astrocytes after neocortical stab wound injury. Glia 59, 800-809. doi: 10.1002/glia.21152

Kopan, R., and Ilagan, M. X. (2009). The canonical notch signaling pathway: unfolding the activation mechanism. Cell 137, 216-233. doi: 10.1016/j.cell.2009. 03.045

Kordelas, L., Rebmann, V., Ludwig, A. K., Radtke, S., Ruesing, J., Doeppner, T. R., et al. (2014). MSC-derived exosomes: a novel tool to treat therapyrefractory graft-versus-host disease. Leukemia 28, 970-973. doi: 10.1038/leu. 2014.41

Krueger, N. X., and Saito, H. (1992). A human transmembrane protein-tyrosinephosphatase, PTP zeta, is expressed in brain and has an $\mathrm{N}$-terminal receptor domain homologous to carbonic anhydrases. Proc. Natl. Acad. Sci. U S A 89, 7417-7421. doi: 10.1073/pnas.89.16.7417
Kwok, J. C., Dick, G., Wang, D., and Fawcett, J. W. (2011). Extracellular matrix and perineuronal nets in CNS repair. Dev. Neurobiol. 71, 1073-1089. doi: 10. 1002/dneu.20974

Lamba, D. A., Karl, M. O., Ware, C. B., and Reh, T. A. (2006). Efficient generation of retinal progenitor cells from human embryonic stem cells. Proc. Natl. Acad. Sci. U S A 103, 12769-12774. doi: 10.1073/pnas.0601990103

Lamba, D. A., McUsic, A., Hirata, R. K., Wang, P. R., Russell, D., and Reh, T. A. (2010). Generation, purification and transplantation of photoreceptors derived from human induced pluripotent stem cells. PLoS One 5:e8763. doi: 10. 1371/journal.pone.0008763

Lang, B., Liu, H. L., Liu, R., Feng, G. D., Jiao, X. Y., and Ju, G. (2004). Astrocytes in injured adult rat spinal cord may acquire the potential of neural stem cells. Neuroscience 128, 775-783. doi: 10.1016/j.neuroscience.2004.06.033

Lau, E., and Margolis, R. U. (2010). Inhibitors of slit protein interactions with the heparan sulphate proteoglycan glypican-1: potential agents for the treatment of spinal cord injury. Clin. Exp. Pharmacol. Physiol. 37, 417-421. doi: 10.1111/j. 1440-1681.2009.05318.x

Laywell, E. D., Dörries, U., Bartsch, U., Faissner, A., Schachner, M., and Steindler, D. A. (1992). Enhanced expression of the developmentally regulated extracellular matrix molecule tenascin following adult brain injury. Proc. Natl. Acad. Sci. US A 89, 2634-2638. doi: 10.1073/pnas.89.7.2634

Lee, B., Clarke, D., Al Ahmad, A., Kahle, M., Parham, C., Auckland, L., et al. (2011). Perlecan domain V is neuroprotective and proangiogenic following ischemic stroke in rodents. J. Clin. Invest. 121, 3005-3023. doi: 10.1172/JCI 46358

Lee, J. K., Kim, J. E., Sivula, M., and Strittmatter, S. M. (2004). Nogo receptor antagonism promotes stroke recovery by enhancing axonal plasticity. J. Neurosci. 24, 6209-6217. doi: 10.1523/jneurosci.1643-04.2004

Leitinger, B., and Hohenester, E. (2007). Mammalian collagen receptors. Matrix Biol. 26, 146-155. doi: 10.1016/j.matbio.2006.10.007

Lendahl, U., Zimmerman, L. B., and McKay, R. D. (1990). CNS stem cells express a new class of intermediate filament protein. Cell 60, 585-595. doi: 10.1016/00928674(90)90662-x

Leonard, W. J., and Lin, J. X. (2000). Cytokine receptor signaling pathways. J. Allergy Clin. Immunol. 105, 877-888. doi: 10.1067/mai.2000.106899

Levine, J. M. (1994). Increased expression of the NG2 chondroitin-sulfate proteoglycan after brain injury. J. Neurosci. 14, 4716-4730.

Levison, S. W., Jiang, F. J., Stoltzfus, O. K., and Ducceschi, M. H. (2000). IL-6-type cytokines enhance epidermal growth factor-stimulated astrocyte proliferation. Glia 32, 328-337. doi: 10.1002/1098-1136(200012)32:3<328::aid-glia110>3.0. co;2-7

Li, L., Lundkvist, A., Andersson, D., Wilhelmsson, U., Nagai, N., Pardo, A. C., et al. (2008). Protective role of reactive astrocytes in brain ischemia. J. Cereb. Blood Flow Metab. 28, 468-481. doi: 10.1038/sj.jcbfm.9600546

Licht, T., Goshen, I., Avital, A., Kreisel, T., Zubedat, S., Eavri, R., et al. (2011). Reversible modulations of neuronal plasticity by VEGF. Proc. Natl. Acad. Sci. US A 108, 5081-5086. doi: 10.1073/pnas.1007640108

Liebscher, T., Schnell, L., Schnell, D., Scholl, J., Schneider, R., Gullo, M., et al. (2005). Nogo-A antibody improves regeneration and locomotion of spinal cordinjured rats. Ann. Neurol. 58, 706-719. doi: 10.1002/ana.20627

Liesi, P., and Kauppila, T. (2002). Induction of type IV collagen and other basement-membrane-associated proteins after spinal cord injury of the adult rat may participate in formation of the glial scar. Exp. Neurol. 173, 31-45. doi: 10. 1006/exnr.2001.7800

Liesi, P., Kaakkola, S., Dahl, D., and Vaheri, A. (1984). Laminin is induced in astrocytes of adult brain by injury. EMBO J. 3, 683-686.

Lim, D. A., Tramontin, A. D., Trevejo, J. M., Herrera, D. G., García-Verdugo, J. M., and Alvarez-Buylla, A. (2000). Noggin antagonizes BMP signaling to create a niche for adult neurogenesis. Neuron 28, 713-726. doi: 10.1016/s08966273(00)00148-3

Lin, T. N., Kim, G. M., Chen, J. J., Cheung, W. M., He, Y. Y., and Hsu, C. Y. (2003). Differential regulation of thrombospondin-1 and thrombospondin-2 after focal cerebral ischemia/reperfusion. Stroke 34, 177-186. doi: 10.1161/01. str.0000047100.84604.ba

Lindholm, D., Castrén, E., Kiefer, R., Zafra, F., and Thoenen, H. (1992). Transforming growth factor-beta 1 in the rat brain: increase after injury and inhibition of astrocyte proliferation. J. Cell Biol. 117, 395-400. doi: 10.1083/jcb.117. 2.395 
Lindholm, D., Hengerer, B., Zafra, F., and Thoenen, H. (1990). Transforming growth factor-beta 1 stimulates expression of nerve growth factor in the rat CNS. Neuroreport 1, 9-12. doi: 10.1097/00001756-199009000-00003

Liu, Y., and Rao, M. S. (2004). Glial progenitors in the CNS and possible lineage relationships among them. Biol. Cell 96, 279-290. doi: 10.1111/j.1768-322x. 2004.tb01416.x

Liu, Y., Wang, X., Lu, C. C., Kerman, R., Steward, O., Xu, X. M., et al. (2008). Repulsive Wnt signaling inhibits axon regeneration after CNS injury. J. Neurosci. 28, 8376-8382. doi: 10.1523/JNEUROSCI.1939-08.2008

Lladó, J., Haenggeli, C., Maragakis, N. J., Snyder, E. Y., and Rothstein, J. D. (2004). Neural stem cells protect against glutamate-induced excitotoxicity and promote survival of injured motor neurons through the secretion of neurotrophic factors. Mol. Cell. Neurosci. 27, 322-331. doi: 10.1016/j.mcn.2004. 07.010

Lozito, T. P., Jackson, W. M., Nesti, L. J., and Tuan, R. S. (2014). Human mesenchymal stem cells generate a distinct pericellular zone of MMP activities via binding of MMPs and secretion of high levels of TIMPs. Matrix Biol. 34, 132-143. doi: 10. 1016/j.matbio.2013.10.003

Ludwig, A. K., and Giebel, B. (2012). Exosomes: small vesicles participating in intercellular communication. Int. J. Biochem. Cell Biol. 44, 11-15. doi: 10.1016/j. biocel.2011.10.005

Maki, T., Liang, A. C., Miyamoto, N., Lo, E. H., and Arai, K. (2013). Mechanisms of oligodendrocyte regeneration from ventricular-subventricular zone-derived progenitor cells in white matter diseases. Front. Cell. Neurosci. 7:275. doi: 10. 3389/fncel.2013.00275

Maness, P. F., and Schachner, M. (2007). Neural recognition molecules of the immunoglobulin superfamily: signaling transducers of axon guidance and neuronal migration. Nat. Neurosci. 10, 19-26. doi: 10.1038/nn1827

Manns, R. P., Cook, G. M., Holt, C. E., and Keynes, R. J. (2012). Differing semaphorin $3 \mathrm{~A}$ concentrations trigger distinct signaling mechanisms in growth cone collapse. J. Neurosci. 32, 8554-8559. doi: 10.1523/jneurosci.5964-11.2012

Maroof, A. M., Keros, S., Tyson, J. A., Ying, S. W., Ganat, Y. M., Merkle, F. T., et al. (2013). Directed differentiation and functional maturation of cortical interneurons from human embryonic stem cells. Cell Stem Cell 12, 559-572. doi: 10.1016/j.stem.2013.04.008

Martino, G., Pluchino, S., Bonfanti, L., and Schwartz, M. (2011). Brain regeneration in physiology and pathology: the immune signature driving therapeutic plasticity of neural stem cells. Physiol. Rev. 91, 1281-1304. doi: 10.1152/physrev. 00032.2010

Massouh, M., and Saghatelyan, A. (2010). De-routing neuronal precursors in the adult brain to sites of injury: role of the vasculature. Neuropharmacology 58, 877-883. doi: 10.1016/j.neuropharm.2009.12.021

McKeon, R. J., Höke, A., and Silver, J. (1995). Injury-induced proteoglycans inhibit the potential for laminin-mediated axon growth on astrocytic scars. Exp. Neurol. 136, 32-43. doi: 10.1006/exnr.1995.1081

McKeon, R. J., Jurynec, M. J., and Buck, C. R. (1999). The chondroitin sulfate proteoglycans neurocan and phosphacan are expressed by reactive astrocytes in the chronic CNS glial scar. J. Neurosci. 19, 10778-10788.

McKeon, R. J., Schreiber, R. C., Rudge, J. S., and Silver, J. (1991). Reduction of neurite outgrowth in a model of glial scarring following CNS injury is correlated with the expression of inhibitory molecules on reactive astrocytes. J. Neurosci. 11, 3398-3411.

McTigue, D. M., Popovich, P. G., Morgan, T. E., and Stokes, B. T. (2000). Localization of transforming growth factor-betal and receptor mRNA after experimental spinal cord injury. Exp. Neurol. 163, 220-230. doi: 10.1006/exnr. 2000.7372

Meng, K., Rodriguez-Peña, A., Dimitrov, T., Chen, W., Yamin, M., Noda, M., et al. (2000). Pleiotrophin signals increased tyrosine phosphorylation of beta betacatenin through inactivation of the intrinsic catalytic activity of the receptortype protein tyrosine phosphatase beta/zeta. Proc. Natl. Acad. Sci. U S A 97, 2603-2608. doi: 10.1073/pnas.020487997

Midwood, K., Sacre, S., Piccinini, A. M., Inglis, J., Trebaul, A., Chan, E., et al. (2009). Tenascin-C is an endogenous activator of toll-like receptor 4 that is essential for maintaining inflammation in arthritic joint disease. Nat. Med. 15, 774-780. doi: 10.1038/nm.1987

Milev, P., Chiba, A., Häring, M., Rauvala, H., Schachner, M., Ranscht, B., et al. (1998a). High affinity binding and overlapping localization of neurocan and phosphacan/protein-tyrosine phosphatase-zeta/beta with tenascin-R, amphoterin and the heparin-binding growth-associated molecule. J. Biol. Chem. 273, 6998-7005. doi: 10.1074/jbc.273.12.6998

Milev, P., Monnerie, H., Popp, S., Margolis, R. K., and Margolis, R. U. (1998b). The core protein of the chondroitin sulfate proteoglycan phosphacan is a high-affinity ligand of fibroblast growth factor- 2 and potentiates its mitogenic activity. J. Biol. Chem. 273, 21439-21442. doi: 10.1074/jbc.273.34.21439

Milner, R., Crocker, S. J., Hung, S., Wang, X., Frausto, R. F., and del Zoppo, G. J. (2007). Fibronectin- and vitronectin-induced microglial activation and matrix metalloproteinase- 9 expression is mediated by integrins alpha5betal and alphavbeta5. J. Immunol. 178, 8158-8167. doi: 10.4049/jimmunol.178.12. 8158

Möller, J. C., Klein, M. A., Haas, S., Jones, L. L., Kreutzberg, G. W., and Raivich, G. (1996). Regulation of thrombospondin in the regenerating mouse facial motor nucleus. Glia 17, 121-132. doi: 10.1002/(sici)1098-1136(199606)17:2<121::aidglia4>3.3.co;2-b

Morawski, M., Brückner, G., Jager, C., Seeger, G., Matthews, R. T., and Arendt, T. (2012). Involvement of perineuronal and perisynaptic extracellular matrix in Alzheimer's disease neuropathology. Brain Pathol. 22, 547-561. doi: 10.1111/j. 1750-3639.2011.00557.x

Morgan, T. E., Nichols, N. R., Pasinetti, G. M., and Finch, C. E. (1993). TGF-beta 1 mRNA increases in macrophage/microglial cells of the hippocampus in response to deafferentation and kainic acid-induced neurodegeneration. Exp. Neurol. 120, 291-301. doi: 10.1006/exnr.1993.1063

Moritz, S., Lehmann, S., Faissner, A., and von Holst, A. (2008). An induction gene trap screen in neural stem cells reveals an instructive function of the niche and identifies the splicing regulator sam68 as a tenascin-C-regulated target gene. Stem Cells 26, 2321-2331. doi: 10.1634/stemcells.2007-1095

Muir, E. M., Adcock, K. H., Morgenstern, D. A., Clayton, R., von Stillfried, N., Rhodes, K., et al. (2002). Matrix metalloproteases and their inhibitors are produced by overlapping populations of activated astrocytes. Brain Res. Mol. Brain Res. 100, 103-117. doi: 10.1016/s0169-328x(02)00132-8

Nag, S., Eskandarian, M. R., Davis, J., and Eubanks, J. H. (2002). Differential expression of vascular endothelial growth factor-A (VEGF-A) and VEGF-B after brain injury. J. Neuropathol. Exp. Neurol. 61, 778-788.

Nakamura, M., and Bregman, B. S. (2001). Differences in neurotrophic factor gene expression profiles between neonate and adult rat spinal cord after injury. Exp. Neurol. 169, 407-415. doi: 10.1006/exnr.2001.7670

Nakic, M., Mitrovic, N., Sperk, G., and Schachner, M. (1996). Kainic acid activates transient expression of tenascin-C in the adult rat hippocampus. J. Neurosci. Res. 44, 355-362. doi: 10.1002/(sici) 1097-4547(19960515)44:4<355::aid-jnr7>3.3. co;2-h

Neman, J., and de Vellis, J. (2012). A method for deriving homogenous population of oligodendrocytes from mouse embryonic stem cells. Dev. Neurobiol. 72, 777788. doi: 10.1002/dneu.22008

Neufeld, G., and Kessler, O. (2008). The semaphorins: versatile regulators of tumour progression and tumour angiogenesis. Nat. Rev. Cancer 8, 632-645. doi: $10.1038 /$ nrc2404

Niclou, S. P., Franssen, E. H., Ehlert, E. M., Taniguchi, M., and Verhaagen, J. (2003). Meningeal cell-derived semaphorin 3A inhibits neurite outgrowth. Mol. Cell. Neurosci. 24, 902-912. doi: 10.1016/s1044-7431(03)00243-4

Nielsen, J., Gotfryd, K., Li, S., Kulahin, N., Soroka, V., Rasmussen, K. K., et al. (2009). Role of glial cell line-derived neurotrophic factor (GDNF)-neural cell adhesion molecule (NCAM) interactions in induction of neurite outgrowth and identification of a binding site for NCAM in the heel region of GDNF. J. Neurosci. 29, 11360-11376. doi: 10.1523/JNEUROSCI.3239-09.2009

Niquet, J., Jorquera, I., Faissner, A., Ben-Ari, Y., and Represa, A. (1995). Gliosis and axonal sprouting in the hippocampus of epileptic rats are associated with an increase of tenascin-C immunoreactivity. J. Neurocytol. 24, 611-624. doi: 10. 1007/bf01257376

Noble, L. J., Donovan, F., Igarashi, T., Goussev, S., and Werb, Z. (2002). Matrix metalloproteinases limit functional recovery after spinal cord injury by modulation of early vascular events. J. Neurosci. 22, 7526-7535.

Obermair, F. J., Schröter, A., and Thallmair, M. (2008). Endogenous neural progenitor cells as therapeutic target after spinal cord injury. Physiology (Bethesda) 23, 296-304. doi: 10.1152/physiol.00017.2008

Overman, J. J., and Carmichael, S. T. (2014). Plasticity in the injured brain: more than molecules matter. Neuroscientist 20, 15-28. doi: 10.1177/ 1073858413491146 
Panchision, D. M. (2009). The role of oxygen in regulating neural stem cells in development and disease. J. Cell. Physiol. 220, 562-568. doi: 10.1002/jcp.21812

Pariser, H., Ezquerra, L., Herradon, G., Perez-Pinera, P., and Deuel, T. F. (2005a). Fyn is a downstream target of the pleiotrophin/receptor protein tyrosine phosphatase beta/zeta-signaling pathway: regulation of tyrosine phosphorylation of Fyn by pleiotrophin. Biochem. Biophys. Res. Commun. 332, 664-669. doi: 10. 1016/j.bbrc.2005.05.007

Pariser, H., Perez-Pinera, P., Ezquerra, L., Herradon, G., and Deuel, T. F. (2005b). Pleiotrophin stimulates tyrosine phosphorylation of beta-adducin through inactivation of the transmembrane receptor protein tyrosine phosphatase beta/zeta. Biochem. Biophys. Res. Commun. 335, 232-239. doi: 10.1016/j.bbrc.2005. 07.060

Pasterkamp, R. J., Giger, R. J., Ruitenberg, M. J., Holtmaat, A. J., De Wit, J., De Winter, F., et al. (1999). Expression of the gene encoding the chemorepellent semaphorin III is induced in the fibroblast component of neural scar tissue formed following injuries of adult but not neonatal CNS. Mol. Cell. Neurosci. 13, 143-166. doi: 10.1006/mcne.1999.0738

Patel, J., Channon, K. M., and McNeill, E. (2013). The downstream regulation of chemokine receptor signalling: implications for atherosclerosis. Mediators Inflamm. 2013:459520. doi: 10.1155/2013/459520

Pekny, M., and Nilsson, M. (2005). Astrocyte activation and reactive gliosis. Glia 50, 427-434. doi: 10.1002/glia.20207

Pekny, M., Wilhelmsson, U., and Pekna, M. (2014). The dual role of astrocyte activation and reactive gliosis. Neurosci. Lett. 565C, 30-38. doi: 10.1016/j.neulet. 2013.12.071

Petrasek, T., Prokopova, I., Bahnik, S., Schonig, K., Berger, S., Vales, K., et al. (2014). Nogo-A downregulation impairs place avoidance in the Carousel maze but not spatial memory in the morris water maze. Neurobiol. Learn. Mem. 107, 42-49. doi: 10.1016/j.nlm.2013.10.015

Petrosyan, H. A., Hunanyan, A. S., Alessi, V., Schnell, L., Levine, J., and Arvanian, V. L. (2013). Neutralization of inhibitory molecule NG2 improves synaptic transmission, retrograde transport and locomotor function after spinal cord injury in adult rats. J. Neurosci. 33, 4032-4043. doi: 10.1523/JNEUROSCI.470212.2013

Piccin, D., and Morshead, C. M. (2011). Wnt signaling regulates symmetry of division of neural stem cells in the adult brain and in response to injury. Stem Cells 29, 528-538. doi: 10.1002/stem.589

Pizzorusso, T., Medini, P., Berardi, N., Chierzi, S., Fawcett, J. W., and Maffei, L. (2002). Reactivation of ocular dominance plasticity in the adult visual cortex. Science 298, 1248-1251. doi: 10.1126/science. 1072699

Pluchino, S., Muzio, L., Imitola, J., Deleidi, M., Alfaro-Cervello, C., Salani, G., et al. (2008). Persistent inflammation alters the function of the endogenous brain stem cell compartment. Brain 131, 2564-2578. doi: 10.1093/brain/awn 198

Pluchino, S., Zanotti, L., Rossi, B., Brambilla, E., Ottoboni, L., Salani, G., et al. (2005). Neurosphere-derived multipotent precursors promote neuroprotection by an immunomodulatory mechanism. Nature 436, 266-271. doi: 10 . 1038/nature03889

Pozzi, A., Wary, K. K., Giancotti, F. G., and Gardner, H. A. (1998). Integrin alphalbetal mediates a unique collagen-dependent proliferation pathway in vivo. J. Cell Biol. 142, 587-594. doi: 10.1083/jcb.142.2.587

Pyka, M., Wetzel, C., Aguado, A., Geissler, M., Hatt, H., and Faissner, A. (2011). Chondroitin sulfate proteoglycans regulate astrocyte-dependent synaptogenesis and modulate synaptic activity in primary embryonic hippocampal neurons. Eur. J. Neurosci. 33, 2187-2202. doi: 10.1111/j.1460-9568.2011.07690.x

Quaglia, X., Beggah, A. T., Seidenbecher, C., and Zurn, A. D. (2008). Delayed priming promotes CNS regeneration post-rhizotomy in Neurocan and Brevicandeficient mice. Brain 131, 240-249. doi: 10.1093/brain/awm279

Rapraeger, A. C., Krufka, A., and Olwin, B. B. (1991). Requirement of heparan sulfate for bFGF-mediated fibroblast growth and myoblast differentiation. Science 252, 1705-1708. doi: 10.1126/science.1646484

Rauch, U., Clement, A., Retzler, C., Fröhlich, L., Fässler, R., Göhring, W., et al. (1997). Mapping of a defined neurocan binding site to distinct domains of tenascin-C. J. Biol. Chem. 272, 26905-26912. doi: 10.1074/jbc.272.43.26905

Resovi, A., Pinessi, D., Chiorino, G., and Taraboletti, G. (2014). Current understanding of the thrombospondin-1 interactome. Matrix Biol. doi: 10.1016/j. matbio.2014.01.012. [Epub ahead of print].

Reya, T., and Clevers, H. (2005). Wnt signalling in stem cells and cancer. Nature 434, 843-850. doi: $10.1038 /$ nature03319
Ricard-Blum, S. (2011). The collagen family. Cold Spring Harb. Perspect. Biol. 3:a004978. doi: 10.1101/cshperspect.a004978

Rigato, F., Garwood, J., Calco, V., Heck, N., Faivre-Sarrailh, C., and Faissner, A. (2002). Tenascin-C promotes neurite outgrowth of embryonic hippocampal neurons through the alternatively spliced fibronectin type III BD domains via activation of the cell adhesion molecule F3/contactin. J. Neurosci. 22, 6596-6609.

Robel, S., Berninger, B., and Götz, M. (2011). The stem cell potential of glia: lessons from reactive gliosis. Nat. Rev. Neurosci. 12, 88-104. doi: 10.1038/ nrn2978

Rolando, C., Parolisi, R., Boda, E., Schwab, M. E., Rossi, F., and Buffo, A. (2012). Distinct roles of nogo-a and nogo receptor 1 in the homeostatic regulation of adult neural stem cell function and neuroblast migration. J. Neurosci. 32, 1778817799. doi: 10.1523/JNEUROSCI.3142-12.2012

Roll, L., Mittmann, T., Eysel, U. T., and Faissner, A. (2012). The laser lesion of the mouse visual cortex as a model to study neural extracellular matrix remodeling during degeneration, regeneration and plasticity of the CNS. Cell Tissue Res. 349, 133-145. doi: 10.1007/s00441-011-1313-4

Rolls, A., Shechter, R., and Schwartz, M. (2009). The bright side of the glial scar in CNS repair. Nat. Rev. Neurosci. 10, 235-241. doi: 10.1038/nrn2591

Ronca, F., Andersen, J. S., Paech, V., and Margolis, R. U. (2001). Characterization of slit protein interactions with glypican-1. J. Biol. Chem. 276, 29141-29147. doi: $10.1074 /$ jbc.m100240200

Rosenkranz, K., Kumbruch, S., Lebermann, K., Marschner, K., Jensen, A., Dermietzel, R., et al. (2010). The chemokine SDF-1/CXCL12 contributes to the 'homing' of umbilical cord blood cells to a hypoxic-ischemic lesion in the rat brain. J. Neurosci. Res. 88, 1223-1233. doi: 10.1002/jnr.22292

Rostène, W., Dansereau, M. A., Godefroy, D., Van Steenwinckel, J., Reaux-Le Goazigo, A., Mélik-Parsadaniantz, S., et al. (2011). Neurochemokines: a menage a trois providing new insights on the functions of chemokines in the central nervous system. J. Neurochem. 118, 680-694. doi: 10.1111/j.1471-4159.2011. 07371.x

Salanga, C. L., O'Hayre, M., and Handel, T. (2009). Modulation of chemokine receptor activity through dimerization and crosstalk. Cell. Mol. Life Sci. 66, 1370-1386. doi: 10.1007/s00018-008-8666-1

Samson, A. L., and Medcalf, R. L. (2006). Tissue-type plasminogen activator: a multifaceted modulator of neurotransmission and synaptic plasticity. Neuron 50, 673-678. doi: 10.1016/j.neuron.2006.04.013

Sarkar, S., Raymick, J., and Schmued, L. (2012). Temporal progression of kainic acid induced changes in vascular laminin expression in rat brain with neuronal and glial correlates. Curr. Neurovasc. Res. 9, 110-119. doi: 10. 2174/156720212800410867

Sasaki, N., Kurisu, J., and Kengaku, M. (2010). Sonic hedgehog signaling regulates actin cytoskeleton via Tiam1-Racl cascade during spine formation. Mol. Cell. Neurosci. 45, 335-344. doi: 10.1016/j.mcn.2010.07.006

Savitz, S. I., Cramer, S. C., Wechsler, L., and Consortium, S. (2014). Stem cells as an emerging paradigm in stroke 3 : enhancing the development of clinical trials. Stroke 45, 634-639. doi: 10.1161/STROKEAHA.113.003379

Schachtrup, C., Ryu, J. K., Helmrick, M. J., Vagena, E., Galanakis, D. K., Degen, J. L., et al. (2010). Fibrinogen triggers astrocyte scar formation by promoting the availability of active TGF-beta after vascular damage. J. Neurosci. 30, 58435854. doi: 10.1523/JNEUROSCI.0137-10.2010

Schlessinger, J., and Ullrich, A. (1992). Growth factor signaling by receptor tyrosine kinases. Neuron 9, 383-391. doi: 10.1016/0896-6273(92)90177-F

Schmandke, A., Schmandke, A., and Schwab, M. E. (2014). Nogo-A: multiple roles in CNS development, maintenance and disease. Neuroscientist 20, 372-386. doi: $10.1177 / 1073858413516800$

Schwab, M. E., and Strittmatter, S. M. (2014). Nogo limits neural plasticity and recovery from injury. Curr. Opin. Neurobiol. 27C, 53-60. doi: 10.1016/j.conb. 2014.02.011

Scott-Drew, S., and ffrench-Constant, C. (1997). Expression and function of thrombospondin-1 in myelinating glial cells of the central nervous system. J. Neurosci. Res. 50, 202-214. doi: 10.1002/(sici)10974547(19971015)50:2<202::aid-jnr9>3.0.co;2-j

Seidenfaden, R., Desoeuvre, A., Bosio, A., Virard, I., and Cremer, H. (2006). Glial conversion of SVZ-derived committed neuronal precursors after ectopic grafting into the adult brain. Mol. Cell. Neurosci. 32, 187-198. doi: 10.1016/j. mcn.2006.04.003 
Semenov, M. V., Habas, R., Macdonald, B. T., and He, X. (2007). SnapShot: noncanonical Wnt signaling pathways. Cell 131, 1378.e1-1378.e2. doi: 10.1016/j.cell. 2007.12.011

Seo, J. H., Miyamoto, N., Hayakawa, K., Pham, L. D., Maki, T., Ayata, C., et al. (2013). Oligodendrocyte precursors induce early blood-brain barrier opening after white matter injury. J. Clin. Invest. 123, 782-786. doi: 10.1172/JCI65863

Sharma, A., Pollett, M. A., Plant, G. W., and Harvey, A. R. (2012a). Changes in mRNA expression of class 3 semaphorins and their receptors in the adult rat retino-collicular system after unilateral optic nerve injury. Invest. Ophthalmol. Vis. Sci. 53, 8367-8377. doi: 10.1167/iovs.12-10799

Sharma, K., Selzer, M. E., and Li, S. (2012b). Scar-mediated inhibition and CSPG receptors in the CNS. Exp. Neurol. 237, 370-378. doi: 10.1016/j.expneurol.2012. 07.009

Shen, Q., Wang, Y., Kokovay, E., Lin, G., Chuang, S. M., Goderie, S. K., et al. (2008). Adult SVZ stem cells lie in a vascular niche: a quantitative analysis of niche cellcell interactions. Cell Stem Cell 3, 289-300. doi: 10.1016/j.stem.2008.07.026

Shimada, I. S., LeComte, M. D., Granger, J. C., Quinlan, N. J., and Spees, J. L. (2012). Self-renewal and differentiation of reactive astrocyte-derived neural stem/progenitor cells isolated from the cortical peri-infarct area after stroke. J. Neurosci. 32, 7926-7940. doi: 10.1523/JNEUROSCI.4303-11.2012

Shimada, I. S., Peterson, B. M., and Spees, J. L. (2010). Isolation of locally derived stem/progenitor cells from the peri-infarct area that do not migrate from the lateral ventricle after cortical stroke. Stroke 41, e552-e560. doi: 10. 1161/STROKEAHA.110.589010

Siddiqui, S., Horvat-Brocker, A., and Faissner, A. (2009). Comparative screening of glial cell types reveals extracellular matrix that inhibits retinal axon growth in a chondroitinase ABC-resistant fashion. Glia 57, 1420-1438. doi: 10.1002/glia. 20860

Silver, J., and Miller, J. H. (2004). Regeneration beyond the glial scar. Nat. Rev. Neurosci. 5, 146-156. doi: 10.1038/nrn1326

Singh, P., Carraher, C., and Schwarzbauer, J. E. (2010). Assembly of fibronectin extracellular matrix. Annu. Rev. Cell Dev. Biol. 26, 397-419. doi: 10. 1146/annurev-cellbio-100109-104020

Siri, A., Knäuper, V., Veirana, N., Caocci, F., Murphy, G., and Zardi, L. (1995). Different susceptibility of small and large human tenascin-C isoforms to degradation by matrix metalloproteinases. J. Biol. Chem. 270, 8650-8654. doi: 10 . 1074/jbc.270.15.8650

Sirko, S., Behrendt, G., Johansson, P. A., Tripathi, P., Costa, M., Bek, S., et al. (2013). Reactive glia in the injured brain acquire stem cell properties in response to sonic hedgehog. [corrected]. Cell Stem Cell 12, 426-439. doi: 10.1016/j.stem.2013. 01.019

Sirko, S., Neitz, A., Mittmann, T., Horvat-Bröcker, A., von Holst, A., Eysel, U. T., et al. (2009). Focal laser-lesions activate an endogenous population of neural stem/progenitor cells in the adult visual cortex. Brain 132, 2252-2264. doi: 10 . 1093/brain/awp043

Siu, R., Fladd, C., and Rotin, D. (2007). N-cadherin is an in vivo substrate for protein tyrosine phosphatase sigma (PTPsigma) and participates in PTPsigmamediated inhibition of axon growth. Mol. Cell. Biol. 27, 208-219. doi: 10 1128/mcb.00707-06

Smith, G. M., and Hale, J. H. (1997). Macrophage/Microglia regulation of astrocytic tenascin: synergistic action of transforming growth factor-beta and basic fibroblast growth factor. J. Neurosci. 17, 9624-9633.

Smith-Thomas, L. C., Stevens, J., Fok-Seang, J., Faissner, A., Rogers, J. H., and Fawcett, J. W. (1995). Increased axon regeneration in astrocytes grown in the presence of proteoglycan synthesis inhibitors. J. Cell Sci. 108(Pt. 3), 1307-1315.

Sobel, R. A. (1998). The extracellular matrix in multiple sclerosis lesions. J. Neuropathol. Exp. Neurol. 57, 205-217. doi: 10.1097/00005072-199803000-00001

Sofroniew, M. V. (2009). Molecular dissection of reactive astrogliosis and glial scar formation. Trends Neurosci. 32, 638-647. doi: 10.1016/j.tins.2009.08.002

Soleman, S., Filippov, M. A., Dityatev, A., and Fawcett, J. W. (2013). Targeting the neural extracellular matrix in neurological disorders. Neuroscience 253, 194-213. doi: 10.1016/j.neuroscience.2013.08.050

Southwell, D. G., Froemke, R. C., Alvarez-Buylla, A., Stryker, M. P., and Gandhi, S. P. (2010). Cortical plasticity induced by inhibitory neuron transplantation. Science 327, 1145-1148. doi: 10.1126/science.1183962

Steigemann, P., Molitor, A., Fellert, S., Jäckle, H., and Vorbrüggen, G. (2004). Heparan sulfate proteoglycan syndecan promotes axonal and myotube guidance by slit/robo signaling. Curr. Biol. 14, 225-230. doi: 10.1016/s0960-9822(04) 00007-7

Stichel, C. C., Kappler, J., Junghans, U., Koops, A., Kresse, H., and Müller, H. W. (1995). Differential expression of the small chondroitin/dermatan sulfate proteoglycans decorin and biglycan after injury of the adult rat brain. Brain Res. 704, 263-274. doi: 10.1016/0006-8993(95)01131-5

Stumm, R. K., Rummel, J., Junker, V., Culmsee, C., Pfeiffer, M., Krieglstein, J., et al. (2002). A dual role for the SDF-1/CXCR4 chemokine receptor system in adult brain: isoform-selective regulation of SDF-1 expression modulates CXCR4dependent neuronal plasticity and cerebral leukocyte recruitment after focal ischemia. J. Neurosci. 22, 5865-5878.

Su, Z., Niu, W., Liu, M. L., Zou, Y., and Zhang, C. L. (2014). In vivo conversion of astrocytes to neurons in the injured adult spinal cord. Nat. Commun. 5:3338. doi: $10.1038 /$ ncomms4338

Sugimoto, K., Nishioka, R., Ikeda, A., Mise, A., Takahashi, H., Yano, H., et al. (2014). Activated microglia in a rat stroke model express NG2 proteoglycan in peri-infarct tissue through the involvement of TGF- $\beta 1$. Glia 62 , 185-198. doi: 10.1002/glia.22598

Swindle, C. S., Tran, K. T., Johnson, T. D., Banerjee, P., Mayes, A. M., Griffith, L., et al. (2001). Epidermal growth factor (EGF)-like repeats of human tenascin$\mathrm{C}$ as ligands for EGF receptor. J. Cell Biol. 154, 459-468. doi: 10.1083/jcb. 200103103

Takahashi, K., and Yamanaka, S. (2006). Induction of pluripotent stem cells from mouse embryonic and adult fibroblast cultures by defined factors. Cell 126, 663676. doi: 10.1016/j.cell.2006.07.024

Tate, C. C., García, A. J., and LaPlaca, M. C. (2007a). Plasma fibronectin is neuroprotective following traumatic brain injury. Exp. Neurol. 207, 13-22. doi: 10.1016/j.expneurol.2007.05.008

Tate, C. C., Tate, M. C., and LaPlaca, M. C. (2007b). Fibronectin and laminin increase in the mouse brain after controlled cortical impact injury. J. Neurotrauma 24, 226-230. doi: 10.1089/neu.2006.0043

Thier, M., Wörsdörfer, P., Lakes, Y. B., Gorris, R., Herms, S., Opitz, T., et al. (2012). Direct conversion of fibroblasts into stably expandable neural stem cells. Cell Stem Cell 10, 473-479. doi: 10.1016/j.stem.2012.03.003

Thored, P., Arvidsson, A., Cacci, E., Ahlenius, H., Kallur, T., Darsalia, V., et al. (2006). Persistent production of neurons from adult brain stem cells during recovery after stroke. Stem Cells 24, 739-747. doi: 10.1634/stemcells. 2005-0281

Tom, V. J., Doller, C. M., Malouf, A. T., and Silver, J. (2004). Astrocyte-associated fibronectin is critical for axonal regeneration in adult white matter. J. Neurosci. 24, 9282-9290. doi: 10.1523/jneurosci.2120-04.2004

Tornero, D., Wattananit, S., Grønning Madsen, M., Koch, P., Wood, J., Tatarishvili, J., et al. (2013). Human induced pluripotent stem cell-derived cortical neurons integrate in stroke-injured cortex and improve functional recovery. Brain 136, 3561-3577. doi: 10.1093/brain/awt278

Treilleux, I., Mallein-Gerin, F., le Guellec, D., and Herbage, D. (1992). Localization of the expression of type I, II, III collagen and aggrecan core protein genes in developing human articular cartilage. Matrix 12, 221-232. doi: 10.1016/s09348832(11)80065-X

Um, J. W., and Ko, J. (2013). LAR-RPTPs: synaptic adhesion molecules that shape synapse development. Trends Cell Biol. 23, 465-475. doi: 10.1016/j.tcb.2013. 07.004

van Horssen, J., Dijkstra, C. D., and de Vries, H. E. (2007). The extracellular matrix in multiple sclerosis pathology. J. Neurochem. 103, 1293-1301. doi: 10.1111/j. 1471-4159.2007.04897.x

von Holst, A. (2008). Tenascin C in stem cell niches: redundant, permissive or instructive? Cells Tissues Organs 188, 170-177. doi: 10.1159/000112848

von Holst, A., Egbers, U., Prochiantz, A., and Faissner, A. (2007). Neural stem/progenitor cells express 20 tenascin C isoforms that are differentially regulated by Pax6. J. Biol. Chem. 282, 9172-9181. doi: 10.1074/jbc.m608067200

von Holst, A., Sirko, S., and Faissner, A. (2006). The unique 473HDChondroitinsulfate epitope is expressed by radial glia and involved in neural precursor cell proliferation. J. Neurosci. 26, 4082-4094. doi: 10.1523/jneurosci. 0422-06.2006

Vutskits, L., Djebbara-Hannas, Z., Zhang, H., Paccaud, J. P., Durbec, P., Rougon, G., et al. (2001). PSA-NCAM modulates BDNF-dependent survival and differentiation of cortical neurons. Eur. J. Neurosci. 13, 1391-1402. doi: 10.1046/j.0953816x.2001.01516.x 
Wade, A., Robinson, A. E., Engler, J. R., Petritsch, C., James, C. D., and Phillips, J. J. (2013). Proteoglycans and their roles in brain cancer. FEBS J. 280, 2399-2417. doi: $10.1111 /$ febs. 12109

Wahl, S., Barth, H., Ciossek, T., Aktories, K., and Mueller, B. K. (2000). Ephrin-A5 induces collapse of growth cones by activating Rho and Rho kinase. J. Cell Biol. 149, 263-270. doi: 10.1083/jcb.149.2.263

Wang, X., Chen, W., Liu, W., Wu, J., Shao, Y., and Zhang, X. (2009b). The role of thrombospondin-1 and transforming growth factor-beta after spinal cord injury in the rat. J. Clin. Neurosci. 16, 818-821. doi: 10.1016/j.jocn.2008.09.014

Wang, L., Shi, J., van Ginkel, F. W., Lan, L., Niemeyer, G., Martin, D. R., et al. (2009a). Neural stem/progenitor cells modulate immune responses by suppressing T lymphocytes with nitric oxide and prostaglandin E2. Exp. Neurol. 216, 177-183. doi: 10.1016/j.expneurol.2008.11.017

Wanner, I. B., Deik, A., Torres, M., Rosendahl, A., Neary, J. T., Lemmon, V. P., et al. (2008). A new in vitro model of the glial scar inhibits axon growth. Glia 56, 1691-1709. doi: 10.1002/glia.20721

Widestrand, A., Faijerson, J., Wilhelmsson, U., Smith, P. L., Li, L., Sihlbom, C., et al. (2007). Increased neurogenesis and astrogenesis from neural progenitor cells grafted in the hippocampus of GFAP-/- Vim-/- mice. Stem Cells 25, 2619 2627. doi: 10.1634/stemcells.2007-0122

Wiese, S., Karus, M., and Faissner, A. (2012). Astrocytes as a source for extracellular matrix molecules and cytokines. Front. Pharmacol. 3:120. doi: 10.3389/fphar. 2012.00120

Wilhelmsson, U., Li, L., Pekna, M., Berthold, C. H., Blom, S., Eliasson, C., et al. (2004). Absence of glial fibrillary acidic protein and vimentin prevents hypertrophy of astrocytic processes and improves post-traumatic regeneration. J. Neurosci. 24, 5016-5021. doi: 10.1523/jneurosci.0820-04.2004

Xiao, Q., Du, Y., Wu, W., and Yip, H. K. (2010). Bone morphogenetic proteins mediate cellular response and, together with Noggin, regulate astrocyte differentiation after spinal cord injury. Exp. Neurol. 221, 353-366. doi: 10.1016/j. expneurol.2009.12.003

Xiao, M. J., Han, Z., Shao, B., and Jin, K. (2009). Notch signaling and neurogenesis in normal and stroke brain. Int. J. Physiol. Pathophysiol. Pharmacol. 1, 192-202.

Xu, J. C., Xiao, M. F., Jakovcevski, I., Sivukhina, E., Hargus, G., Cui, Y. F., et al. (2014). The extracellular matrix glycoprotein tenascin-R regulates neurogenesis during development and in the adult dentate gyrus of mice. J. Cell Sci. 127, 641652. doi: $10.1242 /$ jcs. 137612

Yamaguchi, Y. (2001). Heparan sulfate proteoglycans in the nervous system: their diverse roles in neurogenesis, axon guidance and synaptogenesis. Semin. Cell Dev. Biol. 12, 99-106. doi: 10.1006/scdb.2000.0238

Yamamoto, S., Nagao, M., Sugimori, M., Kosako, H., Nakatomi, H., Yamamoto, N., et al. (2001). Transcription factor expression and notch-dependent regulation of neural progenitors in the adult rat spinal cord. J. Neurosci. 21, 9814-9823.

Yamashita, T., Ninomiya, M., Hernández Acosta, P., García-Verdugo, J. M., Sunabori, T., and Sakaguchi, M. (2006). Subventricular zone-derived neuroblasts migrate and differentiate into mature neurons in the post-stroke adult striatum. J. Neurosci. 26, 6627-6636. doi: 10.1523/jneurosci.0149-06.2006

Yan, K., Zhang, R., Sun, C., Chen, L., Li, P., Liu, Y., et al. (2013). Bone marrowderived mesenchymal stem cells maintain the resting phenotype of microglia and inhibit microglial activation. PLoS One 8:e84116. doi: 10.1371/journal. pone. 0084116
Yang, H., Xiao, Z. C., Becker, B., Hillenbrand, R., Rougon, G., and Schachner, M. (1999). Role for myelin-associated glycoprotein as a functional tenascin-R receptor. J. Neurosci. Res. 55, 687-701. doi: 10.1002/(sici)10974547(19990315)55:6<687::aid-jnr4>3.3.co;2-y

Yayon, A., Klagsbrun, M., Esko, J. D., Leder, P., and Ornitz, D. M. (1991). Cell surface, heparin-like molecules are required for binding of basic fibroblast growth factor to its high affinity receptor. Cell 64, 841-848. doi: 10.1016/00928674(91)90512-w

Ye, Q., and Miao, Q. L. (2013). Experience-dependent development of perineuronal nets and chondroitin sulfate proteoglycan receptors in mouse visual cortex. Matrix Biol. 32, 352-363. doi: 10.1016/j.matbio.2013.04.001

Yokosaki, Y., Matsuura, N., Higashiyama, S., Murakami, I., Obara, M., Yamakido, M., et al. (1998). Identification of the ligand binding site for the integrin alpha9 betal in the third fibronectin type III repeat of tenascin-C. J. Biol. Chem. 273, 11423-11428. doi: 10.1074/jbc.273.19.11423

You, J., Hong, S. Q., Zhang, M. Y., Zhao, H. L., Liu, T. Z., Zhou, H. L., et al. (2012). Passive immunization with tenascin-R (TN-R) polyclonal antibody promotes axonal regeneration and functional recovery after spinal cord injury in rats. Neurosci. Lett. 525, 129-134. doi: 10.1016/j.neulet.2012. 08.002

Zeng, H., Guo, M., Martins-Taylor, K., Wang, X., Zhang, Z., Park, J. W., et al. (2010). Specification of region-specific neurons including forebrain glutamatergic neurons from human induced pluripotent stem cells. PLoS One 5:e11853. doi: 10.1371/journal.pone.0011853

Zhang, S., Xia, Y. Y., Lim, H. C., Tang, F. R., and Feng, Z. W. (2010). NCAMmediated locomotor recovery from spinal cord contusion injury involves neuroprotection, axon regeneration and synaptogenesis. Neurochem. Int. 56, 919-929. doi: 10.1016/j.neuint.2010.03.023

Zhao, R. R., Andrews, M. R., Wang, D., Warren, P., Gullo, M., Schnell, L., et al. (2013). Combination treatment with anti-Nogo-A and chondroitinase ABC is more effective than single treatments at enhancing functional recovery after spinal cord injury. Eur. J. Neurosci. 38, 2946-2961. doi: 10.1111/ejn.12276

Zimmermann, D. R., and Dours-Zimmermann, M. T. (2008). Extracellular matrix of the central nervous system: from neglect to challenge. Histochem. Cell Biol. 130, 635-653. doi: 10.1007/s00418-008-0485-9

Conflict of Interest Statement: The authors declare that the research was conducted in the absence of any commercial or financial relationships that could be construed as a potential conflict of interest.

Received: 26 May 2014; accepted: 18 July 2014; published online: 19 August 2014. Citation: Roll L and Faissner A (2014) Influence of the extracellular matrix on endogenous and transplanted stem cells after brain damage. Front. Cell. Neurosci. 8:219. doi: 10.3389/fncel.2014.00219

This article was submitted to the journal Frontiers in Cellular Neuroscience.

Copyright (C) 2014 Roll and Faissner. This is an open-access article distributed under the terms of the Creative Commons Attribution License (CC BY). The use, distribution or reproduction in other forums is permitted, provided the original author(s) or licensor are credited and that the original publication in this journal is cited, in accordance with accepted academic practice. No use, distribution or reproduction is permitted which does not comply with these terms. 